\title{
An experimentally verified numerical model of finned heat pipes in crossflow
}

\author{
John R. Stark $\mathrm{a}^{*}$ \\ Nourouddin Sharifi ${ }^{\mathrm{a}}$ \\ Theodore L. Bergman ${ }^{\mathrm{a}}$ \\ Amir Faghri ${ }^{\mathrm{b}}$ \\ ${ }^{a}$ Department of Mechanical Engineering, The University of Kansas, \\ 1530 W. $15^{\text {th }}$ Street 3138, Lawrence, KS 66045, USA \\ ${ }^{\mathrm{b}}$ Department of Mechanical Engineering, The University of Connecticut, \\ 191 Auditorium Road, Storrs, CT 06269-3139, USA
}

*Corresponding Author

John R. Stark

John.Robert.Stark@gmail.com

Ph: +1 5152914101 


\begin{abstract}
A numerical model is developed to predict heat rates associated with a heat pipe whose finned condenser section is subjected to external forced convection. Multiphase, conjugate heat transfer inside the heat pipe is predicted using a 2-dimensional model, while fluid flow and convection heat transfer within the fin array is described with a coupled 3-dimensional shear stress transport (SST) model. Predictions of local temperatures and overall heat rates are verified experimentally. The SST model is also validated with 3-dimensional direct simulations that show highly timedependent, 3-dimensional phenomena in the fin array. A previously unreported phenomenon, localized depression of temperatures in the heat pipe wall, is presented and parametric simulations reveal the sensitivity of system performance to the number of fins and the air velocity in the fin array.
\end{abstract}

\title{
Keywords
}

Heat pipe; numerical modeling; fins; fin arrays 


\section{Nomenclature}

$\begin{array}{ll}A & \text { area }\left(\mathrm{m}^{2}\right) \\ D & \text { diameter }(\mathrm{m}) \\ \mathrm{F}_{1}, \mathrm{~F}_{2} & \text { SST blending functions } \\ g & \text { gravitational acceleration }\left(\mathrm{m} / \mathrm{s}^{2}\right) \\ G r & \text { Grashof number } \\ h & \text { convection coefficient }\left(\mathrm{W} / \mathrm{m}^{2} \mathrm{~K}\right) \\ H & \text { height }(\mathrm{m}) \\ k & \text { thermal conductivity }(\mathrm{W} / \mathrm{m} \mathrm{K}) \\ L & \text { length }(\mathrm{m}) \\ m & \text { fin constant } \\ N & \text { number of fins } \\ p & \text { pressure }(\mathrm{Pa}) \\ P_{\kappa} & \text { SST production term }\left(\mathrm{kg} / \mathrm{m} \mathrm{s}^{3}\right) \\ q " & \text { heat flux }\left(\mathrm{W} / \mathrm{m}^{2}\right) \\ Q & \text { heat rate }(\mathrm{W}) \\ R & \text { thermal resistance }(\mathrm{K} / \mathrm{W}) \\ R e & \text { Reynolds number } \\ r, z, \theta & \text { coordinate directions } \\ S & \text { fin pitch }(\mathrm{m}), \text { turbulent strain rate }\left(\mathrm{s}^{-1}\right) \\ S t & \text { Strouhal number } \\ T & \text { temperature }\left({ }^{\circ} \mathrm{C}\right) \\ t & \text { time }(\mathrm{s}), \text { thickness }(\mathrm{m}) \\ u & \text { velocity }(\mathrm{m} / \mathrm{s}) \\ V & \text { average air velocity }(\mathrm{m} / \mathrm{s}) \\ W & \text { width }(\mathrm{m}) \\ x, y, z & \text { coordinate directions } \\ G r e e k & \\ \alpha & \\ \alpha, \beta_{1}, \beta_{2} & \text { thermal diffusivity }\left(\mathrm{m}^{2} / \mathrm{s}\right) \\ \beta & \text { SST model constants } \\ \kappa & \text { thermal expansion coefficient }\left(\mathrm{K}^{-1}\right) \\ \mu & \text { reduced temperature } T-T_{\infty}\left({ }^{\circ} \mathrm{C}\right), \text { angular direction } \\ v & \text { turbulent kinetic energy }\left(\mathrm{m}^{2} / \mathrm{s}^{2}\right) \\ \rho & \text { dynamic viscosity }(\mathrm{kg} / \mathrm{m} \mathrm{s}) \\ \sigma_{k}, \sigma_{\omega}, \sigma_{\omega 2} & \text { kinematic viscosity }\left(\mathrm{m}^{2} / \mathrm{s}\right) \\ & \text { density }\left(\mathrm{kg} / \mathrm{m}^{3}\right) \\ & \text { specific rate of turbulence dissipation }\left(\mathrm{s}^{-1}\right) \\ & \end{array}$




$\begin{array}{ll}\text { Superscripts } & \\ - & \text { average } \\ \text { Subscripts } & \\ 0 & \text { reference } \\ 2,2 \mathrm{c} & \text { fin radius, corrected fin radius } \\ 2 \mathrm{D}, 3 \mathrm{D} & \text { 2- or 3-dimensional } \\ a & \text { adiabatic, air } \\ a g & \text { aerogel } \\ \text { Al } & \text { aluminum } \\ a r & \text { Airloy } \\ c & \text { condenser } \\ c h & \text { channel } \\ \text { conv } & \text { convection } \\ d & \text { downstream } \\ e & \text { evaporator } \\ \text { eff } & \text { effective } \\ \text { exp } & \text { experimental } \\ f & \text { fin } \\ h p & \text { heat pipe } \\ h s & \text { heat spreader } \\ i & \text { case index } \\ \text { min, max } & \text { minimum, maximum } \\ \text { SST } & \text { shear stress transport } \\ \text { tot } & \text { total } \\ t p & \text { thermal paste } \\ t s & \text { top fin surface } \\ \text { turb } & \text { turbulent } \\ u & \text { upstream } \\ v & \text { heat pipe vapor } \\ w & \\ w i & \text { inlet } \\ \infty & \end{array}$




\section{Introduction}

As is well known, heat pipes (HPs) can pose thermal resistances that are orders of magnitude smaller than those associated with conduction within high thermal conductivity materials of similar dimension [1-3]. Recent reviews [4-13] have thoroughly described both HP applications and their principles of operation. Due to the remarkably small thermal resistances posed by HPs, the heat transfer capability of HP systems is often limited by, for example, convective resistances associated with external fluid flow about the HP condenser and/or evaporation sections. Hence, external fins or fin arrays are often employed to reduce the overall thermal resistances of such systems [14-22].

Numerical modeling has been used to analyze heat transfer processes both $(i)$ within HPs [22-32] and (ii) external to HPs such as those equipped with exterior fin arrays [19-22]. Both approaches have employed simplifying assumptions. For example, interior modeling often employs accurate descriptions of the evaporation, condensation, and heat transfer processes within the HP itself, but is hampered by the specification of idealized external thermal boundary conditions at the HP evaporator and condensation sections. Alternatively, recently-reported simulations provide an accurate prediction of the external convective heat transfer processes, but typically treat heat transfer within the HP in a simplified manner [19-21]. Recent investigations describe advances that have been made by developing overall HP system models that include detailed descriptions of both internal and external heat transfer processes. However, these models have been limited to 2D systems [22, 26-28].

For a finned HP subjected to 3D external forced convection, a unified and full 3D approach to solve both the internal and external heat transfer processes concurrently would be computationally expensive. Moreover, detailed 3D predictions of phenomena within the HP may not be needed in some cases due to the multiphase (evaporation and condensation) processes that are affiliated with relatively small thermal resistances. To the authors' knowledge, full 3D predictions of heat transfer within both the interior and exterior to a HP have not been reported in the literature.

The objective of this study is to develop and demonstrate a novel computational methodology to couple 2D internal and 3D external simulations for a common configuration; a 
vertical HP with isothermal conditions at its lower evaporator section, and unsteady 3D convective conditions external to its upper finned condenser section. The model is computationally less expensive than a full 3D simulation and, as will become evident, can satisfactorily replicate measurements of various heat transfer quantities.

\section{Numerical model}

As shown in Fig. 1a, an externally-finned HP of circular cross section and length $L_{h p}=L_{e}$ $+L_{a}+L_{c}$ is oriented vertically, with an evaporator section of length $L_{e}$ positioned beneath the adiabatic and air-cooled condenser sections of lengths $L_{a}$ and $L_{c}$, respectively. The condenser section is finned, with air flowing through the fin array. The finned HP is shown installed in a flow channel in a manner consistent with an experimental setup described later.

A novel overall model, to be presented, consists of two coupled sub-models. The first describes axisymmetric, multiphase heat transfer and fluid flow within the HP. The second describes conduction processes within the HP and the 3D single phase convection external to the HP condenser section. The two sub-models are coupled as will be described shortly. Predictions of the overall model are verified with experimental data, and the model is used to parametrically investigate the HP system performance and reveal previously-unobserved thermal phenomena within the HP.

\subsection{HP sub-model}

A HP sub-model is used to solve the 2D, axisymmetric equations that govern the transient evaporation and condensation processes within an internally-wicked HP, as well as the fluid flow and heat transfer (vapor phase advection, and conduction) within the HP. Details of the model, including the descriptive equations, are available in Sharifi et al. [26]. Due to their length, they will not be repeated here.

The computational domain for the HP sub-model (shown in detail in Fig. 1 of [26] and in Fig. 1a) is comprised of the HP wall, wick, and vapor regions. The region $\left(0 \leq z \leq L_{h p} ; 0<r \leq r_{v}\right)$ contains the vapor phase of the HP working fluid. Heat transfer in this region is governed by conservation of mass, $r$ - and $z$-momentum, and energy, as laid out in Eqs. (1) through (8) of [26]. The wick $\left(r_{v}<r \leq r_{w}\right)$ is a porous metal that is assumed to be saturated with the liquid phase of 
the HP working fluid. Following the approach of Cao and Faghri [24], the flow of liquid within the wick is neglected, and thermal equilibrium between the liquid and the wick material is assumed. The $2 \mathrm{D}$ energy equation applied to the wick requires specification of an effective thermal conductivity, as described in Eqs. (9) through (11) of [26] while conduction in the solid HP wall $\left(r_{w}<r \leq r_{h p}\right)$ is described by Eq. (12) of the same reference. Radiation is neglected since all of the solid materials are opaque, temperatures are relatively low, and thermal resistances due to convection are relatively small. Potential contact resistances are also neglected.

The top and bottom end cap surfaces of the HP $\left(z=0, L_{h p}\right)$ are adiabatic. The exterior surface of the evaporator section is of uniform and constant temperature $T_{e}$, while the exterior of the HP condenser section at $L_{e}+L_{a}<z \leq L_{h p}, r=r_{h p}$ experiences two distinct convection-related heat transfer processes; the first is direct convective cooling along the un-finned external surface of the HP condenser section

$$
-\left.k_{w} \frac{\partial T}{\partial r}\right|_{z, r=r_{h p}}=\overline{h_{w}}\left[T\left(z, r=r_{h p}\right)-T_{\infty}\right]=\overline{h_{w}} \theta\left(z, r=r_{h p}\right)
$$

where $\overline{h_{w}}$ is the time and area averaged convection heat transfer coefficient for the exposed (non-finned) portions of the HP condenser section that is determined as will be discussed in Section 2.3. The second process involves radial conduction to the roots of each of the $N$ annular fins of thickness $t_{f}$ and outer radius $r_{2}$. Analytical annular fin analysis [33] is used to generate an effective heat transfer coefficient, which is applied to the fin roots (at $r=r_{h p}$ ) so that

$$
\begin{aligned}
-\left.k_{w} \frac{\partial T}{\partial r}\right|_{z, r=r_{h p}} & =\overline{h_{\mathrm{eff}}} \theta\left(z, r=r_{h p}\right) \\
& =\overline{h_{f}}\left[\frac{2}{t_{f} m} \times \frac{K_{1}\left(m r_{h p}\right) I_{1}\left(m r_{2 c}\right)-I_{1}\left(m r_{h p}\right) K_{1}\left(m r_{2 c}\right)}{K_{0}\left(m r_{h p}\right) I_{1}\left(m r_{2 c}\right)+I_{0}\left(m r_{h p}\right) K_{1}\left(m r_{2 c}\right)}\right] \theta\left(z, r=r_{h p}\right)
\end{aligned}
$$

where $r_{2 c}=r_{2}+t_{f} / 2$ is used to account for convection from all exposed fin surfaces, and $m=\sqrt{2 \overline{h_{f}} / k_{f} t_{f}}$. The parameter $\overline{h_{f}}$ is the time- and area-averaged convection heat transfer coefficient associated with the top, bottom and tips of the fins (determined as discussed in 
Section 2.3), while $I_{0}\left(K_{0}\right)$ and $I_{1}\left(K_{1}\right)$ are modified, zero-order and first-order Bessel functions of the first (second) kind. Eqs. (1) through (12) of [26], specification of an initial, uniform temperature of $27^{\circ} \mathrm{C}$ and zero velocities everywhere, along with the preceding boundary conditions complete the 2D HP model description. Note that, although the problem is steady in the mean, initial conditions are required as the HP code was originally developed to simulate transient conditions in other applications [26]. The governing equations are solved using a finite volume approach [26] with convergence at each time step assumed when residual mean square values $<10^{-6}$ exist across all dependent variables. The grid dependence of the solutions were checked, with a grid of $190 \times 50(z \times r)$ yielding heat rates within $0.8 \%$ of those produced with a grid of $240 \times 70(z \times r)$. Typical computation times ranged from 20 to 40 minutes.

\subsection{Air side sub-model}

The heat transfer coefficients $\overline{h_{w}}$ and $\overline{h_{f}}$ of Eq. (1) are associated with convection resistances that affect (and can dominate) the overall thermal resistance of this HP configuration, and their values are generally unknown. In this study, they are determined by simulating the complex 3D (air) flow through the fin array. Specifically, the convection coefficients are determined using the SST turbulence model, to be described shortly.

As previously discussed, the 3D, multiphase heat transfer within the HP is not modeled because of the expense of the computations. Instead, the vapor region of the HP is replaced in the 3D model by an artificial, stationary, high thermal conductivity medium that mimics the low thermal resistance associated with the evaporation, condensation, and advection processes in the HP vapor region $\left(0<r \leq r_{v}, 0 \leq z \leq L_{h p}\right)$. The effective thermal conductivity $k_{\text {eff, }}$ of the artificial medium is determined through an iterative process, as described in the next sub-section.

Various approaches may be taken to quantify the 3D air side convection processes. Here, a 3D, transient, fully-elliptic direct numerical simulation (DNS) is first employed to accurately predict the air side convection processes. The predictions of the direct simulation are then used to validate a less expensive steady-state, 3D model that utilizes the shear stress transport (SST) approach. Buoyancy forces are accounted for through a Boussinesq approximation [34] in each model, and because the objective of the comparison is to test the ability of the SST model to 
predict time-averaged flow in this complex geometry, isothermal HP and fins are temporarily assumed.

Due to the expense of the direct simulation only a limited number of direct predictions are used to validate the 3D, steady-state model based on Menter's SST turbulence approach [35]. Predictions of both models will be compared with measurements of key heat transfer parameters. To further test the assumption of axisymmetry that is inherent in the 2D HP model, square fins of surface area equal to that of the annular fins of the HP model are considered in the direct and SST models as well as in the companion experiments.

\subsubsection{Direct simulation}

The computational domain includes $(i)$ the isothermal HP and finned condenser section (Fig. 1a) and (ii) the entire air region within the flow channel of Fig. 1b. To capture the dynamics of the air side convection processes, symmetry about the vertical channel mid-plane is not assumed. Conservation of thermal energy is, therefore,

$$
\frac{\partial T}{\partial t}+u_{x} \frac{\partial T}{\partial x}+u_{y} \frac{\partial T}{\partial y}+u_{z} \frac{\partial T}{\partial z}=\alpha\left(\frac{\partial^{2} T}{\partial x^{2}}+\frac{\partial^{2} T}{\partial y^{2}}+\frac{\partial^{2} T}{\partial z^{2}}\right)
$$

The air is assumed to be incompressible with constant properties, with a velocity distribution that is governed by conservation of mass (Eq. (3)) and momentum (Eqs. (4a) through (4c)). The reference state for all properties as well as the Boussinesq approximation [34] is taken to be a temperature of $T_{0}=25^{\circ} \mathrm{C}$ and pressure of $1 \mathrm{~atm}$.

$$
\begin{aligned}
& \frac{\partial u_{x}}{\partial x}+\frac{\partial u_{y}}{\partial y}+\frac{\partial u_{z}}{\partial z}=0 \\
& \frac{\partial u_{x}}{\partial t}+u_{x} \frac{\partial u_{x}}{\partial x}+u_{y} \frac{\partial u_{x}}{\partial y}+u_{z} \frac{\partial u_{x}}{\partial z}=-\frac{1}{\rho} \frac{\partial p}{\partial x}+v\left(\frac{\partial^{2} u_{x}}{\partial x^{2}}+\frac{\partial^{2} u_{x}}{\partial y^{2}}+\frac{\partial^{2} u_{x}}{\partial z^{2}}\right) \\
& \frac{\partial u_{y}}{\partial t}+u_{x} \frac{\partial u_{y}}{\partial x}+u_{y} \frac{\partial u_{y}}{\partial y}+u_{z} \frac{\partial u_{y}}{\partial z}=-\frac{1}{\rho} \frac{\partial p}{\partial y}+v\left(\frac{\partial^{2} u_{y}}{\partial x^{2}}+\frac{\partial^{2} u_{y}}{\partial y^{2}}+\frac{\partial^{2} u_{y}}{\partial z^{2}}\right) \\
& \frac{\partial u_{z}}{\partial t}+u_{x} \frac{\partial u_{z}}{\partial x}+u_{y} \frac{\partial u_{z}}{\partial y}+u_{z} \frac{\partial u_{z}}{\partial z}=-\frac{1}{\rho} \frac{\partial p}{\partial z}+v\left(\frac{\partial^{2} u_{z}}{\partial x^{2}}+\frac{\partial^{2} u_{z}}{\partial y^{2}}+\frac{\partial^{2} u_{z}}{\partial z^{2}}\right)+\left[1-\beta\left(T-T_{o}\right)\right] g
\end{aligned}
$$


Initial conditions used in the direct simulation are uniform temperatures of $T_{\infty}$ and zero velocities everywhere. The velocity and temperature distributions at the channel inlet $(x=0$, Fig. 1(b)) are assumed to be uniform. The reference pressure at $x=L_{c h}$ is set to zero, and the second derivative of temperatures are also zero at the channel exit. No-slip conditions are applied at all solid surfaces and the channel walls are assumed to be adiabatic. The governing equations for the direct simulation are solved using a computational mesh of $36.1 \times 10^{6}$ elements and a time step of 0.001 seconds over an overall simulated duration of 10 seconds. Grid- and time-step independence is discussed in the Appendix. The convergence criterion applied to each time step is for the residual mean squares of all variables to be less than $10^{-5}$. Computation times of several weeks were typically required for each case, requiring 96 GB of RAM on a Dell Precision T7600.

\subsubsection{SST turbulence model}

Predictions generated from the direct simulation (along with experimental measurements) are used to validate the computationally-efficient, steady-state SST model applied to a reduced air side domain (channel half-width) shown in Fig. 1b. The SST model has been shown [36-40] to yield accurate results when employed in conjugate heat transfer applications where flow separation is likely to occur. This model is governed by conservation of energy

$$
u_{x} \frac{\partial T_{i}}{\partial x}+u_{y} \frac{\partial T_{i}}{\partial y}+u_{z} \frac{\partial T_{i}}{\partial z}=\alpha_{i}\left(\frac{\partial^{2} T_{i}}{\partial x^{2}}+\frac{\partial^{2} T_{i}}{\partial y^{2}}+\frac{\partial^{2} T_{i}}{\partial z^{2}}\right) \quad i=f, w, w i, v, \text { and } a
$$

while fluid motion in the air is governed by conservation of mass (Eq. (3)) and conservation of $x$, $y$, and $z$ momentum (Eqs. (6a) through (6c)). The air is again assumed to be incompressible with constant properties. The reference state for properties and the Boussinesq approximation is the same as for the direct simulation.

$$
\begin{aligned}
& u_{x} \frac{\partial u_{x}}{\partial x}+u_{y} \frac{\partial u_{x}}{\partial y}+u_{z} \frac{\partial u_{x}}{\partial z}=-\frac{1}{\rho} \frac{\partial p}{\partial x}+\left(v+v_{\text {turb }}\right)\left(\frac{\partial^{2} u_{x}}{\partial x^{2}}+\frac{\partial^{2} u_{x}}{\partial y^{2}}+\frac{\partial^{2} u_{x}}{\partial z^{2}}\right) \\
& u_{x} \frac{\partial u_{y}}{\partial x}+u_{y} \frac{\partial u_{y}}{\partial y}+u_{z} \frac{\partial u_{y}}{\partial z}=-\frac{1}{\rho} \frac{\partial p}{\partial y}+\left(v+v_{\text {turb }}\right)\left(\frac{\partial^{2} u_{y}}{\partial x^{2}}+\frac{\partial^{2} u_{y}}{\partial y^{2}}+\frac{\partial^{2} u_{y}}{\partial z^{2}}\right)
\end{aligned}
$$




$$
u_{x} \frac{\partial u_{z}}{\partial x}+u_{y} \frac{\partial u_{z}}{\partial y}+u_{z} \frac{\partial u_{z}}{\partial z}=-\frac{1}{\rho} \frac{\partial p}{\partial z}+\left(v+v_{\text {turb }}\right)\left(\frac{\partial^{2} u_{z}}{\partial x^{2}}+\frac{\partial^{2} u_{z}}{\partial y^{2}}+\frac{\partial^{2} u_{z}}{\partial z^{2}}\right)+\left[1-\beta\left(T-T_{o}\right)\right] g
$$

The remaining governing equations (Eqs. (7a) and (7b)) for the air side are from the SST turbulence model. Expressions for the turbulent viscosity and the production terms are included in Eqs. (8a) and (8b), respectively, and all remaining coefficients may be found in Menter [35].

$$
\begin{aligned}
& \rho\left(\frac{\partial\left(u_{x} \kappa\right)}{\partial x}+\frac{\partial\left(u_{y} \kappa\right)}{\partial y}+\frac{\partial\left(u_{z} \kappa\right)}{\partial z}\right)=P_{\kappa}-\beta_{1} \rho \kappa \omega+\frac{\partial}{\partial x}\left[\left(\mu+\sigma_{\kappa} \mu_{\text {turb }}\right) \frac{\partial \kappa}{\partial x}\right]+ \\
& \frac{\partial}{\partial y}\left[\left(\mu+\sigma_{\kappa} \mu_{\text {turb }}\right) \frac{\partial \kappa}{\partial y}\right]+\frac{\partial}{\partial z}\left[\left(\mu+\sigma_{\kappa} \mu_{\text {turb }}\right) \frac{\partial \kappa}{\partial z}\right] \\
& \rho\left(\frac{\partial\left(u_{x} \omega\right)}{\partial x}+\frac{\partial\left(u_{y} \omega\right)}{\partial y}+\frac{\partial\left(u_{z} \omega\right)}{\partial z}\right)=\frac{\alpha_{1}}{v_{\text {turb }}} P_{\kappa}-\beta_{2} \rho \omega^{2}+ \\
& \frac{\partial}{\partial x}\left[\left(\mu+\sigma_{\omega} \mu_{\text {turb }}\right) \frac{\partial \omega}{\partial x}\right]+\frac{\partial}{\partial y}\left[\left(\mu+\sigma_{\omega} \mu_{\text {turb }}\right) \frac{\partial \omega}{\partial y}\right]+\frac{\partial}{\partial z}\left[\left(\mu+\sigma_{\omega} \mu_{\text {turb }}\right) \frac{\partial \omega}{\partial z}\right] \\
& 2\left(1-F_{1}\right) \frac{\rho \sigma_{\omega 2}}{\omega}\left(\frac{\partial \kappa \partial \omega}{\partial x^{2}}+\frac{\partial \kappa \partial \omega}{\partial y^{2}}+\frac{\partial \kappa \partial \omega}{\partial z^{2}}\right) \\
& \mu_{\text {turb }}=\rho v_{\text {turb }}=\frac{\rho \alpha_{1} \kappa}{\max \left(\alpha_{1} \omega, \mathrm{SF}_{2}\right)} \quad ; \quad P_{\kappa}=\mu S^{2}
\end{aligned}
$$

Time-averaged symmetry about the vertical channel mid-plane (and zero shear) is exploited to further reduce the computational expense of the air-side SST modeling. An assumed turbulence intensity of $5 \%$ is specified at $x=0$, and the spatial second derivatives of $\kappa$, the turbulent kinetic energy, and $\omega$, the specific rate of turbulent dissipation, are set to zero at the channel outlet. In addition, the spatial derivatives of $\kappa$ and $\omega$ with respect to the outward surface normal of all air-side solid surfaces are set to zero. At the channel inlet, $\kappa$ and $\omega$ are functions of the turbulence intensity, the definition of which is available from Menter [35]. Inlet conditions correspond to uniform channel air velocities and temperatures. The artificial stationary medium (which occupies the HP vapor phase region) is initially assigned an arbitrary, large value of $k_{e f f, v}$. Convergence of the SST model is assumed when residual mean squared (RMS) values $<10^{-6}$ are 
achieved for all dependent variables. Grid independence is discussed in the Appendix. The final computational grids contained $27.8 \times 10^{6}, 100.5 \times 10^{6}$, and $127.2 \times 10^{6}$ elements for 0,3 , and 6 fin cases, respectively. A typical simulation time required for solving the SST model is 9 hours (2.5 hours) for the initial (coupled iteration) cases.

\subsection{SST-HP sub-model coupling}

The SST and HP sub-models are coupled as diagrammed in Fig. 2. The overall simulation is initialized by first solving the steady-state, 3D, SST model. Upon convergence, the areaaveraged convection heat transfer coefficients for the fins, $\overline{h_{f}}$, and the exposed HP condenser wall surfaces, $\overline{h_{w}}$, are determined using

$$
\overline{h_{w}}=\frac{1}{A_{w}} \int_{A_{w}} \frac{q^{\prime \prime}\left(z, r=r_{h p}, \theta\right)}{\theta_{w}} d A_{w} \quad ; \quad \overline{h_{f}}=\frac{1}{A_{f}} \int_{A_{f}} \frac{q^{\prime \prime}\left(z, r=r_{h p}, \theta\right)}{\theta_{f}} d A_{f}
$$

where $\theta \equiv T-T_{\infty}$. Step 1 of the iteration between the two sub-models involves prediction of the HP heat rate, $Q_{h p, 3 \mathrm{D}}$, and the calculated difference between the area-averaged temperatures of the HP evaporator and HP condenser. Predicted values of $Q_{h p}$ and $\Delta T$ defined as

$$
\Delta T_{2 \mathrm{D} \text { or } 3 \mathrm{D}}=T_{e}-\bar{T}_{c}=T_{e}-\frac{1}{A_{c}} \int_{A_{c}} T d A_{c}
$$

are saved for comparison to corresponding quantities predicted by the 2D HP model.

In Step 2, values of $\overline{h_{w}}$ and $\overline{h_{f}}$ predicted by the 3D SST model are used in Eqs.(1a) and

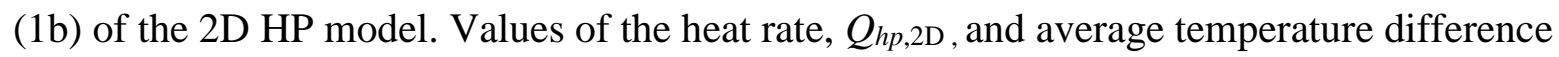
$\Delta T_{2 \mathrm{D}}$ are then obtained. If $\Delta T_{2 \mathrm{D}} \approx \Delta T_{3 \mathrm{D}}$, a new value of $k_{\text {eff, } v}$ is specified, and Steps 1 and 2 are repeated until $\left(\Delta T_{3 \mathrm{D}}-\Delta T_{2 \mathrm{D}}\right) / \Delta T_{2 \mathrm{D}}<0.02$. A comparison of the final predicted values of the HP heat rates obtained by the 2D and 3D models, $Q_{h p, 2 \mathrm{D}}$ and $Q_{h p, 3 \mathrm{D}}$ respectively, is used as a check of the overall modeling strategy. 


\section{Experiments}

Experiments were conducted to validate the various models. They involve a copper- $\mathrm{H}_{2} \mathrm{O}$ HP whose condenser fin array is cooled by forced convection of air, as shown in Figs. 3 and 4.

\subsection{Heat pipe and fins}

The vertically-oriented, copper- $\mathrm{H}_{2} \mathrm{O}$ HP (Enertron HP-HD06DI17500BA) shown in Fig. 3 is of length $L_{h p}=175 \mathrm{~mm}$ and diameter $D_{h p}=6 \mathrm{~mm}$. Wick and wall dimensions, as well as physical and effective properties, along with other HP characteristics are listed elsewhere [22]. The HP evaporator (condenser) section is of length $L_{e}=50.8 \mathrm{~mm}\left(L_{c}=75 \mathrm{~mm}\right)$. The evaporator section is encapsulated by a cylindrical aluminum ( $\left.\mathrm{Al} 2024-\mathrm{T} 4 ; k_{h s}=121 \mathrm{~W} / \mathrm{m} \mathrm{K}\right)$ heat spreader of length $L_{h s}=L_{e}$, outer diameter $25.4 \mathrm{~mm}$, and inner diameter $6.05 \mathrm{~mm}$. Thermal paste (Arctic Silver $5 ; k_{t p}=8.7 \mathrm{~W} / \mathrm{m} \mathrm{K}$ ) is packed within the gap between the HP and the spreader. The heat source is an adhesive-backed electrical patch heater (McMaster 35765K634) of dimensions 50.8 $\mathrm{mm} \times 305 \mathrm{~mm} \times 1.80 \mathrm{~mm}$ that is wrapped around the outer periphery of the heat spreader.

The temperature of the evaporator's exterior wall is deduced by $(i)$ measuring temperatures at two axial locations within the heat spreader at $r=6.35 \mathrm{~mm}$ with $127 \mu \mathrm{m}$ diameter K-type thermocouples, and (ii) using a conduction resistance analysis to bridge the thermal resistances posed by the aluminum and the thin layer of thermal paste. The maximum measured temperature difference between the two thermocouples is less than $0.1^{\circ} \mathrm{C}$, while the largest difference between the average temperature of the thermocouples and exterior surface of the HP evaporator is $2.1^{\circ} \mathrm{C}$, corresponding to the largest heat rate considered here.

The $N$ square aluminum (AL 3003-h14; $k_{f}=159 \mathrm{~W} / \mathrm{m} \mathrm{K}$ ) fins are of planar dimension $L_{f}$ $=W_{f}=100 \mathrm{~mm}$ and thickness $t_{f}=0.97 \mathrm{~mm}$. The fins are evenly spaced, on center, over the condenser length with a pitch of $S=L_{c} /(N+1)$. The fins were first soldered onto the HP with Superior Flux AL27-33-75 solder paste using a standalone jig and oven setup.

\subsection{HP carrier}

Potential conjugate heat transfer effects, as well as parasitic heat losses, are addressed by carefully designing a HP carrier. To minimize outward radial heat losses from the heat spreader, it is embedded in a rectangular bed of aerogel powder (Lumira®; $k_{a g}=0.012 \mathrm{~W} / \mathrm{m} \mathrm{K}$ ) of length 
$L_{a g}=100 \mathrm{~mm}$, width $W_{a g}=80 \mathrm{~mm}$, and height $H_{a g}=90 \mathrm{~mm}$, contained by $18.7 \mathrm{~mm}$ thick acrylic walls. To minimize axial losses and to physically support the HP, cylinders were machined from solid aerogel sheets (Airloy ${ }^{\circledR}$ X103ML; $k_{a r}=0.029 \mathrm{~W} / \mathrm{m} \mathrm{K}$ ) with radial dimensions equal to that of heat spreader. To minimize (i) axial losses to the overlying flow channel and (ii) radial losses from/gains to the HP adiabatic section, a cylindrical pocket of $40 \mathrm{~mm}$ height, $25.4 \mathrm{~mm}$ inner diameter, and $139.7 \mathrm{~mm}$ outer diameter was machined in the top acrylic assembly of the heat pipe carrier and filled with aerogel powder.

After being snapped into place, the top, circular surface of the HP carrier lies flush with the bottom surface of the flow channel. The carrier is secured to the flow channel with small (of diameter $6.35 \mathrm{~mm}$ ), low thermal conductivity Nylon 12-12 screws to further minimize conjugate heat transfer effects. Overall heat losses are predicted to be less than $47 \%$ and $5 \%$ of the power delivered to the patch heater for the experiments involving the lowest $\left(Q_{\mathrm{exp}}=0.61 \mathrm{~W}\right)$ and highest heat rates $\left(Q_{\exp }=36.3 \mathrm{~W}\right)$, respectively.

\subsection{Flow channel}

The flow channel is shown schematically in Fig. 4, along with a second cartesian coordinate system whose origin is at the exit of the flow straightening section ( $x$-direction), the mid-plane of the tunnel ( $y$-direction), and at vertical elevation coincident with the bottom of the HP (z-direction). The interior dimensions of the flow channel are $L_{c h}=2.75 \mathrm{~m}$, interior width of $W_{c h}=200 \mathrm{~mm}$, and height $H_{c h}=75 \mathrm{~mm}$. The centerline of the HP is located at $x=1.33 \mathrm{~m}, y=0$. The flow channel walls are constructed of $18.7 \mathrm{~mm}$ thick acrylic sheet.

The flow channel is operated in suction mode. The inlet air is thermally conditioned by passing it through an inlet plenum comprised of a $100 \mathrm{~mm}$ long packed bed of $12 \mathrm{~mm}$ stainless steel ball bearings followed by a bank of $40 \mathrm{~mm}$ thick, $194 \mathrm{~mm} \times 260 \mathrm{~mm}$ concrete slabs. The slabs are separated by channels of height $3 \mathrm{~mm}$. Flow conditioning is achieved with a bank of thin-walled, $5 \mathrm{~mm}$ diameter plastic cylinders (drinking straws) $197 \mathrm{~mm}$ long. Characterization of the flow channel yielded an isothermal temperature distribution in the $y-z$ plane located at $x=$ $1.28 \mathrm{~m}$. The top wall of the flow channel houses a semitransparent, $0.23 \mathrm{~mm}$ thick Mylar sheet whose bottom surface is flush with the bottom surface of the top channel wall (Figs. 3 and 4). An infrared imaging system (FLIR A300) is mounted in a look-down configuration and used to 
measure the temperature distributions on the top surface of the top fin which was painted with a thin layer of Krylon 1602 ultra-flat paint of emissivity 0.96 in the spectral range of interest [41]. The semitransparent nature of the Mylar window was accounted for when interpreting the infrared temperature information, as discussed in the next section.

The air exits the flow channel through a second set of conditioners and a $100 \mathrm{~mm}$ diameter perforated tube positioned horizontally within the tunnel exit plenum. The air is driven by a fan whose flow rate could be manually adjusted by partially blocking the fan exit. Bulk flow rates were measured using an orifice plate situated in a long straight section of $100 \mathrm{~mm}$ tubing. The pressure drop across the orifice plate was calibrated to bulk flow rates that were inferred by spatially integrating the local velocity distributions within the tunnel. Locations of various 127 $\mu \mathrm{m}$ K-type thermocouples are identified in Fig. 4.

\subsection{Instrumentation and data acquisition}

The patch heater at the HP evaporator section is powered by a DC power supply (Dr. Meter HY3005F-3). A voltmeter (AMPROBE AM-510; accuracy $\pm 0.8 \%$ of reading + 1 LSD; resolution $10 \mathrm{mV}$ ) and ammeter (FLUKE $77 \mathrm{IV}$; accuracy $\pm 1.5 \%$ of reading $+2 \mathrm{LSD}$; resolution $1 \mathrm{~mA}$ ) are used to measure the electric power dissipation within a maximum uncertainty of \pm $0.70 \mathrm{~W}$ (associated with the maximum power considered; $36.3 \mathrm{~W}$ ). Thermocouple and pressure transducer (Omega PX653-01D5V, \pm 0.001 inch $\mathrm{H}_{2} \mathrm{O}$ ) voltages are collected by a data acquisition system (National Instruments cDAQ-9188 XT) at 2 s intervals using LabVIEW software. A hot wire probe (Anemomaster $6035-0 \mathrm{E}$; accuracy $\pm 3 \%$ of reading, resolution 0.01 $\mathrm{m} / \mathrm{s}$ ) was used to measure the local air velocities within the flow channel within a maximum uncertainty of $\pm 0.046 \mathrm{~m} / \mathrm{s}$ (associated with the velocity of $1.5 \mathrm{~m} / \mathrm{s}$ ). All of the welded thermocouples were constructed from the same spools of wire to minimize bias error when reporting temperature differences. The thermocouples were calibrated using the boiling and freezing points of distilled water within an estimated uncertainty $\pm 0.1^{\circ} \mathrm{C}$. Temperatures indicated by the infrared camera (when viewing the HP assembly through the Mylar window) were corrected by developing and using an off-line calibration involving an aluminum heat exchanger of known temperature that was painted with Krylon 1602 and viewed through the Mylar window. The maximum uncertainty associated with reported infrared-measured temperatures is $\pm 0.15^{\circ} \mathrm{C}$. 


\section{Results and discussion}

\subsection{DNS-SST comparison}

DNS predictions were generated using the computational domain of Fig. 1b. These predictions were used to validate the SST model (applied to the channel half-width of Fig. 1b) for $N=3$ fins, $T_{\infty}=25^{\circ} \mathrm{C}$ and inlet velocities of $V=0.5$ and $1.5 \mathrm{~m} / \mathrm{s}$. Since the DNS-SST comparison is meant only to check the ability of the SST model to accurately predict the 3D external flow, an isothermal HP assembly $T_{h p, f}=60^{\circ} \mathrm{C}$, was specified in order to reduce the cost of the comparison. The DNS and SST predictions are both deemed to be grid and time-step independent (Appendix).

Air temperature distributions (at the vertical mid-plane of the channel) generated by the DNS model (at an arbitrary time after quasi-steady conditions are reached) and SST models (steady state) are reported in Fig. 5. For $V=0.5 \mathrm{~m} / \mathrm{s}$, the DNS (Fig. 5a) and SST predictions (Fig. 5c) are similar. Buoyancy forces drive three rising warm wakes that issue downstream from each of the three fins. Since $G r_{H_{c h}} / R e_{H_{c h}}^{2}=0.33$, inertial and buoyancy forces are expected to be of similar magnitude.

For $V=1.5 \mathrm{~m} / \mathrm{s}$ (DNS, Fig. 5b; SST, Fig. $\left.5 \mathrm{~d} ; G r_{H_{c h}} / R e_{H_{c h}}^{2}=0.037\right)$ the DNS predictions involve a complex, time-dependent structure. As expected, the time-averaged SST predictions (Fig. 5d) reveal steeper temperature gradients (higher heat transfer rates) near the solid surfaces, compared to those of Fig. 5c. Buoyancy effects are not evident in the higher velocity predictions.

Temperature distributions in a horizontal plane located midway between the middle and top fins are shown in Fig. 6. Vortex shedding from the vertical HP is evident in the DNS predictions for both the low (Fig. 6a) and high velocity (Fig. 6b) cases. Boundary layer development over the fins is affected by the vortices, with temperature distributions in a horizontal plane (not shown) immediately downstream of the top fin being affected by of the vortex shedding process. The interplay between the fin and HP convection processes, as well as the buoyancy effects of the smaller velocity case, makes specification of $\overline{h_{w}}$ and $\overline{h_{f}}$ using standard correlations prone to large uncertainty. 


\subsection{Comparison of DNS and SST predictions with experimental measurements}

Local air temperatures were measured in the same horizontal planes as included in Fig. 6 using a butt-welded K-type thermocouple held taught and supported between small holes placed in the vertical channel walls. Analysis of air temperatures measured at approximately 3.0 and 6.3 HP diameters downstream of the HP centerline reveals $S t$ values of 0.176 and 0.193 for the low and high velocity cases, respectively. The measured values are in good agreement with $S t$ values for vortex shedding from a plain cylinder in cross flow [42].

Since the experiments involve an operating HP and the DNS model employs the assumption of an isothermal HP-fin assembly, thermal conditions to which the air is exposed are different. Therefore, measured and predicted dimensional air temperatures are not expected to be in agreement. However, a comparison of measured and DNS-predicted dimensionless air temperatures is meaningful. Typical comparisons of time-averaged temperatures measured across the downstream wake averaged over 5 minutes are shown in Fig. 7a (thermocouple placed 3.0 HP diameters downstream of the HP centerline) and Fig. 7b (6.3 HP diameters downstream). Both the time-averaged DNS and steady-state SST predictions are in good agreement with timeaveraged measured dimensionless temperatures, further validating the SST predictions. Predicted values of $\overline{h_{w}}$ and $\overline{h_{f}}$, obtained from the SST and DNS models, are reported in Table 1. The predictions of the two models are in agreement to within \pm 6 percent.

\subsection{Comparison of overall model predictions with experimental measurements}

The results thus far are for an isothermal HP-fin array assembly. To ascertain the performance of the overall (coupled HP and SST) model described in Fig. 2, the isothermal HP assumption is now relaxed. Measured and predicated (both 2D and 3D) heat rates are reported in Table 2 for 8 cases. Also included in the table are the converged values of $k_{\text {eff, },}, \overline{h_{w}}$, and $\overline{h_{f}}$.

Predicted (2D and 3D) heat rates are in good agreement (within 7 percent of the average of the two heat rates) for all cases considered here. Predicted 3D heat rates are consistently higher than their predicted 2D counterparts. This discrepancy may be attributed to non-uniform predicted temperatures in the wall of the HP condenser section, to be discussed shortly. Measured heat rates are consistently lower than predicted heat rates (an average discrepancy of 
10 percent); this discrepancy may be attributed to contact resistances between the HP and the fins that are not accounted for in either (SST or HP) model.

The convection heat transfer coefficients of Table 2 exhibit several expected trends. First, values of the convection coefficients increase as the air speed is increased. Second, heat transfer coefficients for the exposed HP walls are higher than those associated with the fins. Third, the predicted convection coefficients are nearly independent of the evaporator temperatures (for a given air velocity) since buoyancy effects do not dominate. The converged effective thermal conductivity used in the 3D SST model increases as the evaporator temperature increases, reflecting the more vigorous evaporation, condensation, and HP vapor advection associated with the larger overall HP temperature differences.

Predicted (SST) and measured local fin temperatures (for the top surface of the upper square fin) are reported in Fig. 8 for a representative case, $N=6, T_{e}=60^{\circ} \mathrm{C}, T_{\infty}=25^{\circ} \mathrm{C}, V=1.5$ $\mathrm{m} / \mathrm{s}$. Eleven isotherms are shown in Fig. 8, all separated by temperature differences of $1.68^{\circ} \mathrm{C}$. The minimum fin temperature shown for the measurements is $T_{\min } \approx 37.5^{\circ} \mathrm{C}$ and occurs at the outer leading edges of the square fin, while maximum temperatures $\left(T_{\max } \approx 56.0^{\circ} \mathrm{C}\right)$ occur at the fin root. The minimum and maximum SST-predicted temperatures occur at the same locations and are $T_{\min }=37.7^{\circ} \mathrm{C}$ and $T_{\max }=56.2^{\circ} \mathrm{C}$. Advective effects are evident in both the measured and predicted temperature distributions, but regions closer to the fin root have a more uniform temperature distribution in the azimuth direction, $\theta$, of Fig. $1 \mathrm{~b}$. The nearly axisymmetric temperature distribution near the base of the fin gives further credence to the $2 \mathrm{D}$ modeling of the HP taken here. Advective effects are also evident in Fig. 9, which reports measured (both spanwise and streamwise) temperature distributions on the top surface of the upper fin. The 3D SST predictions show similar advective effects as the measurements, while the 2D HP predictions show no dependence on $\theta$, as required. In general the agreement between predicted (2D and 3D) and measured local fin temperatures is considered to be good.

\subsection{Predicted HP wall temperatures}

Predicted temperature distributions along the length of the HP wall $\left(r=r_{h p}\right)$ for both $N=$ 3 and $N=6\left(T_{e}=60^{\circ} \mathrm{C}, V=1.5 \mathrm{~m} / \mathrm{s}\right)$ are shown in Figs. 10a and 10b, respectively, using the modeling approach of Fig. 2. Both figures also include predicted temperature distributions for $N$ 
$=0$ for purposes of comparison. Significant temperature depressions exist within the HP wall adjacent to the fin roots. The thermal depressions are a result of the interplay between the external convection processes, conduction within the fins, and multimode heat transfer within the HP. Depressions predicted by the 2D model are consistently larger than those for the 3D model. This may be attributed to the approximate treatment of the heat transfer within the HP vapor region in the 3D model which is unable to replicate, for example, variations in local condensation rates internal to the HP and, in turn, the correspondingly high local heat transfer rates adjacent to the fin roots. It is well known that increased constriction resistances are associated with large temperature depressions of the type noted here [33]. These resistances will increase the overall thermal resistance of the HP system, and reduce the HP heat rate predicted by the $2 \mathrm{D}$ model relative to those predicted by the $3 \mathrm{D}$ model, consistent with the results of Table 2. To the authors' knowledge, this constriction resistance effect has not been previously reported in HP-related research.

\subsection{Parametric simulations}

Heat rates predicted by the 2D HP and 3D SST models, along with measured heat rate values, are reported graphically in Fig. 11 for $N=0,3$ and $6, T_{\infty}=25^{\circ} \mathrm{C}$, and a range of convective conditions. As evident, heat rates increase as $N, T_{e}$, and $V$ are increased, with general agreement between the heat rates that are predicted and measured.

\subsection{Heat pipe and external thermal resistances}

The detailed predictions of the coupled 2D and 3D models can be used to determine total, heat pipe, and external convection thermal resistances. The total and HP resistances are determined using the expressions $R_{\mathrm{tot}}=\left(T_{e}-T_{\infty}\right) / Q_{h p}$ and $R_{h p}=\left(T_{e}-\bar{T}_{c}\right) / Q_{h p}$, respectively, while the external air convection resistances are calculated from $R_{\mathrm{conv}}=R_{\mathrm{tot}}-R_{h p}$. The HP and convection thermal resistances are assumed to act in series, and $R_{\text {conv }}$ includes the effects of convection directly from the HP and through the external fin arrays. Note that the experimental total thermal resistances are calculated in the same manner as their predicted counterparts, except measured heat rates are used. 
As evident from Table 3, predicted and measured total thermal resistances are in relatively good agreement. The total thermal resistances decrease as $T_{e}, N$, or $V$ increase. In every case, the overall thermal resistance is dominated by the external thermal resistances, suggesting that significantly improved performance could be achieved with optimized external fin arrays.

\subsection{Limitation of the stagnant HP core approach of the 3D SST model}

As discussed, the 3D SST model incorporates an artificial stationary medium of high thermal conductivity in the HP vapor region to approximate the low thermal resistances inside the HP. Values of the effective core thermal conductivity, $k_{\mathrm{eff}, v}$, are determined by employing the coupling strategy of Fig. 2. To estimate the possible influence of non-axisymmetric heat transfer in the HP, several 3D SST simulations were performed for extreme cases in which the stationary core is subdivided into upstream $(0<\theta \leq \pi / 2)$ and downstream $(\pi / 2<\theta \leq \pi)$ halves. To force highly-3D processes within the HP, the effective thermal conductivity of the upstream half is set to $k_{\mathrm{eff}, v, u}=2 k_{\mathrm{eff}, v}$ (or 0 ) while the conductivity of the downstream half is specified to be $k_{\mathrm{eff}, v, d}=0$ (or $\left.2 k_{\mathrm{eff}, v}\right)$.

Predicted temperature distributions on the top surface of the upper fin for the conditions of Fig. 8, using the extreme effective thermal conductivity values, are shown in Fig. 12. As expected, warmer temperatures are pushed upstream for the $k_{\mathrm{eff}, v, d}=0$ case, with the opposite behavior noted for $k_{\mathrm{eff}, v, u}=0$. The temperature distributions, obtained with $k_{\mathrm{eff}, \max }=140,000 \mathrm{~W} / \mathrm{m}$ $\mathrm{K}$, bracket those of Fig. 8. The predicted heat rates are $40.31 \mathrm{~W}$ and $40.40 \mathrm{~W}$ for $k_{\text {eff, }, v, d}=0$ and $k_{\text {eff }, v, u}=0$, respectively. These represent less than 5 percent decrease from the nominal value of $Q_{h p}=42.01 \mathrm{~W}$ reported in Table 2. Similar percentage reductions were observed for the $N=3$ case.

As evident, simply doubling the effective conductivity in one half of the HP vapor region (and setting the conductivity in the other half to zero) has little effect on the overall heat rate, but changes the predicted value of $\Delta T_{3 \mathrm{D}}$ by approximately 20 percent. Usage of the iteration process of Fig. 2 to hone the predictions yields heat rates of 41.67 and $41.68 \mathrm{~W}$ for the $k_{\mathrm{eff}, v, d}=0$ and $k_{\text {eff, }, u}=0$ cases, respectively, with $k_{\text {eff,max }}=200,000 \mathrm{~W} / \mathrm{m} \mathrm{K}$ predicted for both cases. Similar trends were observed for the $N=3$ case. 
From the preceding discussion, it is expected that highly asymmetric conditions within the HP have a minor effect on temperature distributions, and an insignificant effect on the predicted heat transfer rate in finned HP systems.

\section{Conclusions}

A novel modeling strategy, based upon an existing, multiphase 2D HP model that is coupled with a new 3D single-phase (external flow) model has been developed. The 3D external flow sub-model uses the shear stress transport (SST) approach. SST predictions have been validated through a comparison with both direct simulations and experimental measurements. Likewise, the overall model has been validated by comparing its predictions with experimental measurements of local temperatures and heat rates. The model has revealed temperature depressions in the HP wall that can affect the overall thermal resistance of the HP-fin array system. The model has also been used to quantify total heat rates and their sensitivity to external flow conditions and the number of fins in the array. With the overall modeling strategy verified, the model can be exercised to predict a wide array of system performance parameters including but not limited to overall thermal resistances, external flow pressure drops, as well as fan pumping requirements for various HP and of fin array designs.

\section{Acknowledgement}

This material is based upon work supported by the National Science Foundation under Grant Nos. 1435131 (University of Kansas) and 1435233 (University of Connecticut). The authors also wish to thank undergraduate research assistants Will Libeer and Thomas Dunn for their assistance in the construction and validation of the experimental apparatus. 


\section{References}

[1] D.A. Reay, P.A. Kewm R.J. McGlen, Heat Pipes: Theory, Design, and Applications, Sixth ed., Elsevier, Oxford, 2014.

[2] Amir Faghri, Heat Pipe Science and Technology, Taylor \& Francis, Washington, DC, 1995.

[3] A.A. El-Nasr, S.M. El-Haggar, Effective thermal conductivity of heat pipes, Heat and Mass Transfer 32 (1-2) (1996) 97-101.

[4] H. Shabgard, M.J. Allen, N. Sharifi, S.P. Benn, A. Faghri, T.L. Bergman, Heat pipe heat exchangers and heat sinks: opportunities, challenges, applications, analysis, and state of the art, International Journal of Heat and Mass Transfer 89 (2015) 138-158.

[5] W. Srimuang, P. Amatachaya, A review of the applications of heat pipe heat exchangers for heat recovery, Renewable Sustainable Energy Reviews 16 (2012) 4303-4315.

[6] K.S. Ong, Review of heat pipe heat exchangers for enhanced dehumidification and cooling in air conditioning systems, International Journal of Low-Carbon Technologies 0 (2014) 1-8.

[7] A. Mardiana-Idayu, S.B. Riffat, Review on heat recovery technologies for building applications, Renewable and Sustainable Energy Reviews 16 (2) (2012) 1241-255.

[8] M.S. Naghavi, K.S. Ong, M. Mehrali, I.S. Badruddin, H.S.C. Metselaar, A state-of-the-art review on hybrid heat pipe latent heat storage systems, Energy Conversion and Management 105 (2015) 11781204.

[9] A. Faghri, Heat pipes: review, opportunities and challenges, Frontiers in Heat Pipes 5 (1) (2014).

[10] M. Mochizuki, T. Nguyen, K Mashiko, Y. Saito, T. Nguyen, V. Wuttijumnong, A review of heat pipe application including new opportunities, Frontiers in Heat Pipes 2 (1) (2011).

[11] S. Liu, M. Sakr, A comprehensive review on passive heat transfer enhancements in pipe exchangers, Renewable and Sustainable Energy Reviews 19 (2013) 64-81.

[12] H.N. Chaudhry, B.R. Hughes, S.A. Ghani, A review of heat pipe systems for heat recovery and renewable energy applications, Renewable and Sustainable Energy Reviews 16 (4) (2012) 2249-2259.

[13] A. Faghri, Review and advances in heat pipe science and technology, Journal of Heat Transfer 134 (12) (2012) 123001.

[14] E. Okamoto, Y. Fukaya, M. Chikami, Heat Pipe Heat Exchanger, US Patent No. 4537247, 1985.

[15] N.N. Carpenter, Heat Pipe Heat Exchanger, Hudson Products Co., US Patent No. 5379831, 1995.

[16] A. Faghri, T.L. Bergman, N. Sharifi, M.J. Allen, H. Shabgard, J.S. Breit, Energy storage and thermal management using phase change materials in conjunction with heat pipes and foil, foams, or other porous media, US Patent Application No 0284020 A1, 2014.

[17] K.S. Kim, M.H. Won, J.W. Kim, B.J. Back, Heat pipe cooling technology for desktop PC CPU, Applied Thermal Engineering 23 (9) (2003) 1137-1144.

[18] M.A. Abd El-Baky, M.M. Mohamed, Heat pipe heat exchanger for heat recovery in air conditioning, Applied Thermal Engineering 27 (4) (2007) 795-801.

[19] K.A.R. Ismail, C.L.F. Avles, M.S. Modesto, Numerical and experimental study on the solidification of PCM around a vertical axially finned isothermal cylinder, Applied Thermal Engineering 21 (1) (2001) 53-77.

[20] S. Tiari, S. Qiu, Three-dimensional simulation of high temperature latent heat thermal energy storage system assisted by finned heat pipes, Energy Conversion and Management 105 (2015) 260-271.

[21] S. Tiari, S. Qiu, M. Mahdavi, Numerical study of finned heat pipe-assisted thermal energy storage system with high temperature phase change material, Energy Conversion and Management 89 (2015) 833-842.

[22] N. Sharifi, T.L. Bergman, M.J. Allen, A. Faghri, Melting and solidification enhancement using a combined heat pipe, foil approach, International Journal of Heat and Mass Transfer 78 (2014) 930-941. 
[23] M. Mahdavi, S. Qiu, S. Tiari, Numerical investigation of hydrodynamics and thermal performance of a specially configured heat pipe for high-temperature thermal energy storage systems, Applied Thermal Engineering 81 (2015) 325-337.

[24] Y. Cao, A. Faghri, Transient two-dimensional compressible analysis for high-temperature heat pipes with pulsed heat input, Numerical Heat Transfer Applications 18 (4) (1990) 483-502.

[25] N. Zhu, K. Vafai, Vapor and liquid flow in an asymmetrical flat plate heat pipe: a three-dimensional analytical and numerical investigation, International Journal of Heat and Mass Transfer 41 (1) (1998) 159-174.

[26] N. Sharifi, S. Wang, T.L. Bergman, A. Faghri, Heat pipe-assisted melting of a phase change material, International Journal of Heat and Mass Transfer 55 (13-14) (2012) 3458-3469.

[27] N. Sharifi, A. Faghri, T.L. Bergman, C.E. Andraka, Simulation of Heat Pipe-assisted Latent Heat Thermal Energy Storage with Simultaneous Charging and Discharging, International Journal of Heat and Mass Transfer 80 (2015): 170-179.

[28] H. Shabgard, A. Faghri, T.L. Bergman, C.E. Andraka, Numerical simulation of heat pipe-assisted latent heat thermal energy storage unit for dish-stirling systems, Journal of Solar Engineering 136 (2) (2014) 021025-1-021025-12.

[29] N. Zhu, K. Vafai, Numerical and analytical investigation of vapor flow in a disk-shaped heat pipe incorporating secondary flow, International Journal of Heat and Mass Transfer 40 (12) (1997) 28872900.

[30] M. Mahdavi, S. Qui, Mathematical modeling and analysis of steady state performance of a heat pipe network, Applied Thermal Engineering 91 (2015) 556-573.

[31] B. Xiao, A. Faghri, A three-dimensional thermal-fluid analysis of flat heat pipes, International Journal of Heat and Mass Transfer 51 (11-12) (2008) 3113-3126.

[32] J. Rice, A. Faghri, Analysis of porous wick heat pipes, including capillary dry-out limitations, Journal of Thermophysics and Heat Transfer 21 (3) (2007) 475-486.

[33] T.L. Bergman, A.S. Lavine, F.P. Incropera, D.P. Dewitt, Fundamentals of Heat and Mass Transfer, Seventh ed., Wiley, Hoboken, 2011.

[34] E.M. Sparrow, J.P. Abraham, A new buoyancy model replacing the standard pseudo-density difference for internal natural convection in gases, International Journal of Heat and Mass Transfer 46 (19) (2003) 3583-3591.

[35] F.R. Menter, Two-equation eddy-viscosity turbulence models for engineering applications, AIAA Journal, 32 (8) (1994) 1598-1605.

[36] H. Nemati, M. Moghimi, Numerical study of flow over annular-finned tube heat exchangers by different turbulent models, CFD Letters 6 (3) (2014) 101-112.

[37] J.P. Abraham, E.M. Sparrow, J.C.K. Tong, Heat transfer in all pipe flow regimes - laminar, transitional/intermittent, and turbulent, International Journal of Heat and Mass Transfer 52 (2009) 557563.

[38] J.P. Abraham, E.M. Sparrow, W.J. Minkowycz, Internal-flow Nusselt numbers for the low-Reynoldsnumber end of the laminar-to-turbulent transition regime, International Journal of Heat and Mass Transfer 54 (2011) 584-588.

[39] J.P. Abraham, E.M. Sparrow, J.C.K. Tong, D.W. Bettenhausen, Internal flows which transist from turbulent through intermittent to laminar, International Journal of Thermal Sciences 49 (2010) 256-263.

[40] J.C.K. Tong, J.P. Abraham, J.M.Y. Tse, E.M. Sparrow, Impact of chamfer contours to reduce column drag, Engineering and Computational Mechanics 168 (2015) 79-88.

[41] Emissivity of Paint, NASA Jet Propulsion Laboratory, 26 Feb. 2012. $<$ http://master.jpl.nasa.gov/reference/paints.htm>

[42] R.D. Blevins, Flow-induced Vibration, Krieger Publishing Company, Malabar, FL, 1990. 


\section{Appendix. Time step and grid-size independence}

Predictions of the SST simulations, generated using the commercial software Ansys CFX (v16.0), for the $N=0,3$ and 6 fin configurations with $T_{e}=60^{\circ} \mathrm{C}, T_{\infty}=25^{\circ} \mathrm{C}$, and $V=1.5 \mathrm{~m} / \mathrm{s}$ were evaluated for their grid dependence. The grid dependence study for $N=3$, presented here, is representative of all cases. Details of the computational mesh $(\approx 100$ million elements $)$ within the vertical mid-plane of the channel for the $N=3$ case are shown in Fig. A-1. Predictions of the heat transfer rate $Q_{h p, 3 \mathrm{D}}$, overall temperature difference, $\Delta T_{3 \mathrm{D}}$, as well as the convection heat

transfer coefficients, $\overline{h_{f}}$ and $\overline{h_{w}}$ are shown in Table 4 . A grid refinement from 70.6 million to 96.6 million elements yielded a maximum of $0.36 \%$ change in any of parameters, at which point grid independence was considered to be achieved. Adequate mesh sizes utilized for the $N=0$ and 6 fin cases were determined in a similar manner and are 27.8 and 127.2 million elements, respectively.

The $N=3$ DNS simulation with the same $T_{e}=T_{h p, f}=60^{\circ} \mathrm{C}, T_{\infty}$, and $V$ as for the SST cases, was evaluated for grid dependence in a similar manner. This process yielded a satisfactory mesh of 36.1 million elements within the air domain (less than $0.7 \%$ variation relative to predictions generated from a computational grid of 17.7 million elements). Additionally, time step dependence was investigated. Time-averaged DNS results changed by less than $0.1 \%$ when the time step was reduced from 0.005 seconds to 0.001 (which is the time-step used here). 
Table 1. DNS and SST predicted heat transfer coefficients $\left(\mathrm{W} / \mathrm{m}^{2} \mathrm{~K}, N=3, T_{e}=60^{\circ} \mathrm{C}\right)$.

\begin{tabular}{|c|c|c|c|c|}
\hline \multirow{2}{*}{ Case } & \multicolumn{2}{|c|}{$V=0.5 \mathrm{~m} / \mathrm{s}$} & \multicolumn{2}{c|}{$V=1.5 \mathrm{~m} / \mathrm{s}$} \\
\cline { 2 - 5 } & $\overline{h_{f}}$ & $\overline{h_{w}}$ & $\overline{h_{f}}$ & $\overline{h_{w}}$ \\
\hline Time-averaged DNS & 12.93 & 28.96 & 23.24 & 51.38 \\
\hline SST & 13.83 & 31.13 & 25.40 & 58.68 \\
\hline
\end{tabular}

Table 2. Conditions (left) and predicted values (right) for parametric calculations.

\begin{tabular}{|c|c|c|c|c|c|c|c|c|}
\hline \multicolumn{3}{|c|}{ Input parameters } & \multicolumn{6}{|c|}{ Predicted values } \\
\hline \multirow{2}{*}{$N$} & $V$ & $T_{e}$ & $k_{\mathrm{eff}, v}$ & $\overline{h_{w}}$ & $\overline{h_{f}}$ & $Q_{h p, 3 \mathrm{D}}$ & $Q_{h p, 2 \mathrm{D}}$ & $Q_{\text {exp }}$ \\
\hline & $\mathrm{m} / \mathrm{s}$ & ${ }^{\circ} \mathrm{C}$ & $\mathrm{W} / \mathrm{m} \mathrm{K}$ & $\mathrm{W} / \mathrm{m}^{2} \mathrm{~K}$ & $\mathrm{~W} / \mathrm{m}^{2} \mathrm{~K}$ & $\mathrm{~W}$ & $\mathrm{~W}$ & $\mathrm{~W}$ \\
\hline \multirow{4}{*}{3} & \multirow{2}{*}{0.5} & 34.5 & 47,500 & 28.47 & 10.74 & 4.41 & 3.81 & 4.09 \\
\hline & & 60 & 52,000 & 28.46 & 10.74 & 15.86 & 14.07 & 15.40 \\
\hline & \multirow{2}{*}{1.5} & 34.5 & 39,000 & 55.28 & 20.27 & 5.99 & 5.47 & 5.00 \\
\hline & & 60 & 63,000 & 55.29 & 20.27 & 23.06 & 20.66 & 19.34 \\
\hline \multirow{4}{*}{6} & \multirow{2}{*}{0.5} & 34.5 & 35,000 & 26.29 & 11.02 & 7.56 & 6.86 & 5.92 \\
\hline & & 60 & 64,000 & 26.47 & 11.03 & 29.89 & 26.64 & 26.46 \\
\hline & \multirow{2}{*}{1.5} & 34.5 & 32,000 & 51.24 & 19.47 & 10.42 & 9.19 & 7.27 \\
\hline & & 60 & 70,000 & 51.53 & 19.50 & 42.01 & 37.03 & 36.30 \\
\hline
\end{tabular}

Table 3. Conditions (left) and predicted thermal resistances (right) for parametric calculations.

\begin{tabular}{|c|c|c|c|c|c|c|c|c|c|}
\hline \multicolumn{3}{|c|}{ Input parameters } & \multicolumn{3}{|c|}{ Predicted values (2D) } & \multicolumn{3}{|c|}{ Predicted values (3D) } & \multirow{2}{*}{$\begin{array}{c}\begin{array}{c}\text { Measured } \\
\text { values }\end{array} \\
R_{\text {tot }}\end{array}$} \\
\hline \multirow{2}{*}{$N$} & $V$ & $T_{e}$ & $R_{\mathrm{tot}}$ & $R_{h p}$ & $R_{\text {conv }}$ & $R_{\mathrm{tot}}$ & $R_{h p}$ & $R_{\text {conv }}$ & \\
\hline & $\mathrm{m} / \mathrm{s}$ & ${ }^{\circ} \mathrm{C}$ & $\mathrm{K} / \mathrm{W}$ & K/W & $\mathrm{K} / \mathrm{W}$ & $\mathrm{K} / \mathrm{W}$ & $\mathrm{K} / \mathrm{W}$ & $\mathrm{K} / \mathrm{W}$ & $\mathrm{K} / \mathrm{W}$ \\
\hline \multirow{4}{*}{3} & \multirow{2}{*}{0.5} & 34.5 & 2.50 & 0.11 & 2.39 & 2.15 & 0.10 & 2.05 & 2.32 \\
\hline & & 60 & 2.48 & 0.10 & 2.38 & 2.21 & 0.10 & 2.11 & 2.27 \\
\hline & \multirow{2}{*}{1.5} & 34.5 & 1.74 & 0.14 & 1.60 & 1.58 & 0.12 & 1.46 & 1.90 \\
\hline & & 60 & 1.70 & 0.10 & 1.60 & 1.52 & 0.08 & 1.44 & 1.81 \\
\hline \multirow{4}{*}{6} & \multirow{2}{*}{0.5} & 34.5 & 1.38 & 0.16 & 1.22 & 1.25 & 0.14 & 1.11 & 1.60 \\
\hline & & 60 & 1.31 & 0.09 & 1.22 & 1.17 & 0.08 & 1.09 & 1.32 \\
\hline & \multirow{2}{*}{1.5} & 34.5 & 1.03 & 0.17 & 0.86 & 0.91 & 0.15 & 0.76 & 1.31 \\
\hline & & 60 & 0.94 & 0.08 & 0.86 & 0.83 & 0.07 & 0.76 & 0.96 \\
\hline
\end{tabular}


Table 4. Predicted values (right) as a function of the number of elements employed (left).

\begin{tabular}{|c|c|c|c|c|c|}
\hline \multirow{2}{*}{ Nodes } & \multirow{2}{*}{ Elements } & $\overline{h_{w}}$ & $\overline{h_{f}}$ & $Q_{h p, 3 \mathrm{D}}$ & $\Delta T_{3 \mathrm{D}}$ \\
\cline { 3 - 6 } & & $\mathrm{W} / \mathrm{m}^{2} \mathrm{~K}$ & $\mathrm{~W} / \mathrm{m}^{2} \mathrm{~K}$ & $\mathrm{~W}$ & $\mathrm{~K}$ \\
\hline $1.2 \mathrm{E}+07$ & $8.4 \mathrm{E}+06$ & 82.0 & 36.6 & 26.3 & 1.75 \\
\hline $2.2 \mathrm{E}+07$ & $1.5 \mathrm{E}+07$ & 82.7 & 36.7 & 26.4 & 1.75 \\
\hline $2.3 \mathrm{E}+07$ & $1.4 \mathrm{E}+07$ & 71.0 & 25.1 & 22.3 & 1.48 \\
\hline $3.4 \mathrm{E}+07$ & $2.1 \mathrm{E}+07$ & 78.7 & 23.8 & 22.8 & 1.51 \\
\hline $1.0 \mathrm{E}+08$ & $7.1 \mathrm{E}+07$ & 55.3 & 20.3 & 23.3 & 1.53 \\
\hline $1.4 \mathrm{E}+08$ & $9.7 \mathrm{E}+07$ & 55.3 & 20.2 & 23.3 & 1.54 \\
\hline
\end{tabular}




\section{Figure captions}

Fig. 1. Schematic of the physical system. (a) Test section, (b) flow channel. Two separate coordinate systems are shown.

Fig. 2. Coupling of the internal (2D HP) and external (3D SST) numerical models.

Fig. 3. Side view of the test section (finned HP, HP carrier, and flow channel).

Fig. 4. Flow channel (side view).

Fig. 5. Temperature distributions in the channel centerplane, $N=3, T_{e}=T_{h p, f}=60^{\circ} \mathrm{C}$. (a) DNS ( $V$ $=0.5 \mathrm{~m} / \mathrm{s}),(\mathrm{b}) \operatorname{DNS}(V=1.5 \mathrm{~m} / \mathrm{s})$, (c) $\operatorname{SST}(V=0.5 \mathrm{~m} / \mathrm{s})$, (d) $\operatorname{SST}(V=1.5 \mathrm{~m} / \mathrm{s})$. Minimum and maximum temperatures are $T_{\min }=25^{\circ} \mathrm{C}$ and $T_{\max }=52^{\circ} \mathrm{C}$.

Fig. 6. Temperature distributions in horizontal plane midway between fins, $N=3, T_{e}=T_{h p, f}=$ $60^{\circ} \mathrm{C}$. (a) DNS $(V=0.5 \mathrm{~m} / \mathrm{s})$, (b) DNS $(V=1.5 \mathrm{~m} / \mathrm{s})$, (c) SST $(V=0.5 \mathrm{~m} / \mathrm{s})$, (d) SST $(V=1.5$ $\mathrm{m} / \mathrm{s})$. Temperature scale same as Fig. 5.

Fig. 7. Dimensionless DNS, SST, and experimental temperature distributions across thermal wakes, $N=3, T_{e}=60^{\circ} \mathrm{C}, V=0.5 \mathrm{~m} / \mathrm{s}$. (a) $3.0 \mathrm{HP}$ diameters downstream from the HP centerline (b) $6.3 \mathrm{HP}$ diameters downstream from the HP centerline.

Fig. 8. Predicted (upper half) and measured (bottom half) fin top surface temperature distribution for $V=1.5 \mathrm{~m} / \mathrm{s}$ (left to right): $T_{e}=60^{\circ} \mathrm{C}, N=6$. See Section 4.2 for isotherm values.

Fig. 9. Top surface temperature distributions for $V=1.5 \mathrm{~m} / \mathrm{s}, T_{e}=60^{\circ} \mathrm{C}$, and $\theta=0,90^{\circ}$. (a) $N=$ 3, (b) $N=6$.

Fig. 10. Predicted HP wall temperature distributions $\left(r=r_{h p}\right)$ for $T_{e}=60^{\circ} \mathrm{C}$. (a) $N=3$, (b) $N=6$.

Fig. 11. Heat transfer rates versus HP exterior evaporator wall temperatures for different inlet air velocities. (a) $N=0$, (b) $N=3$, (c) $N=6$.

Fig. 12. Predicted fin top surface temperature distributions for $V=1.5 \mathrm{~m} / \mathrm{s}, T_{e}=60^{\circ} \mathrm{C}, N=6$ for $k_{\text {eff }, v, d}=0$ (top half) and $k_{\text {eff }, v, u}=0$ (bottom half). The temperature scale is the same as for Fig. 8.

Fig. A-1. SST computational mesh for $N=3$ determined by the grid independence study. Magnification is increased from left to right. 


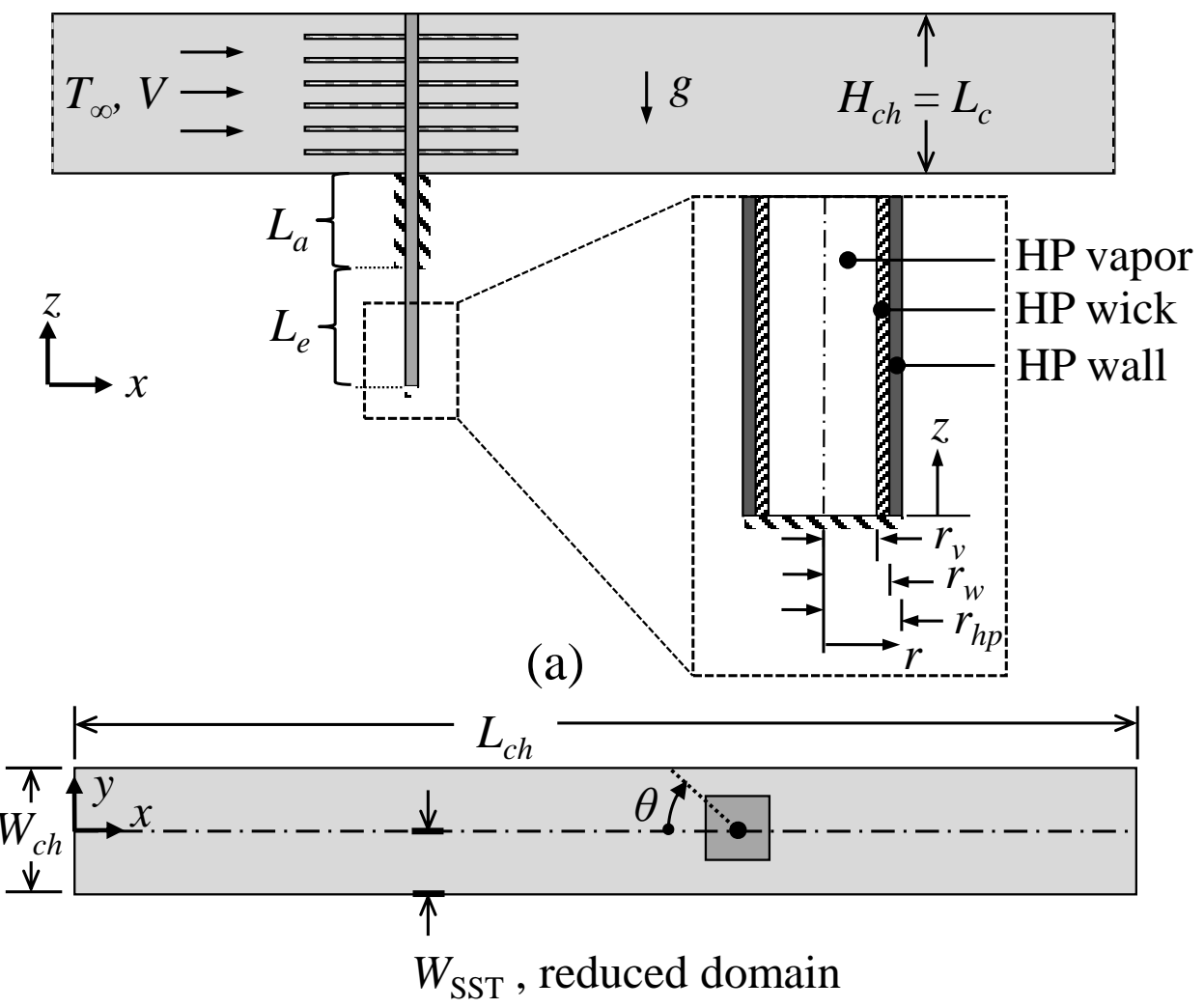

(b)

Fig. 1. 


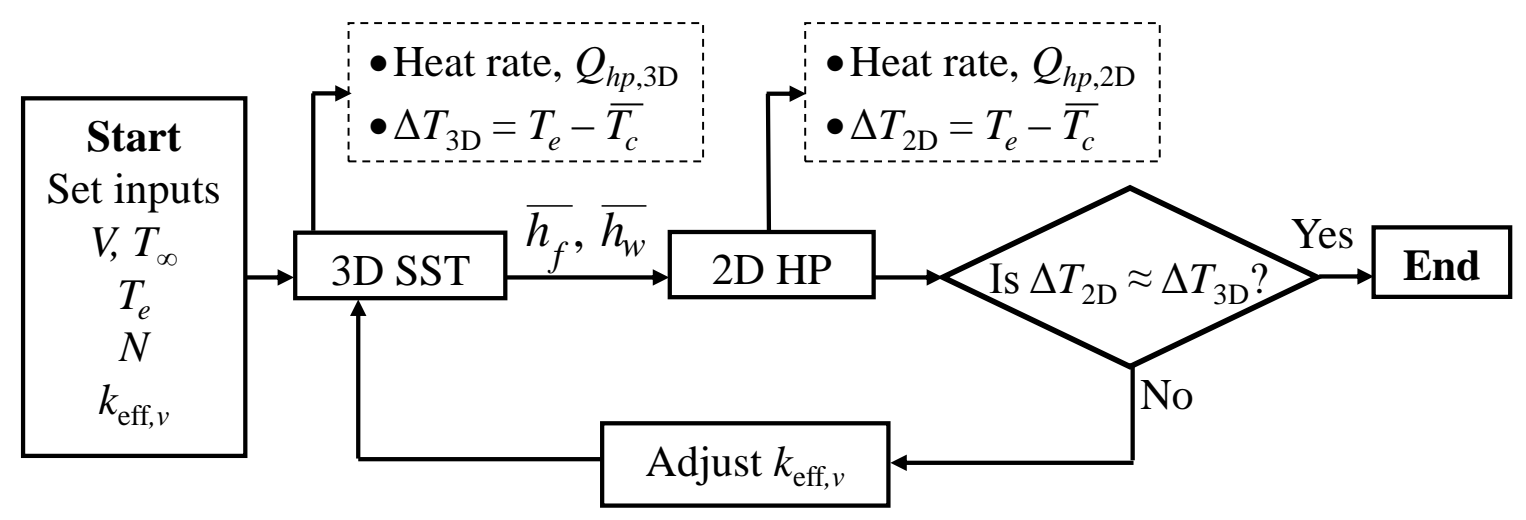

Fig. 2. 


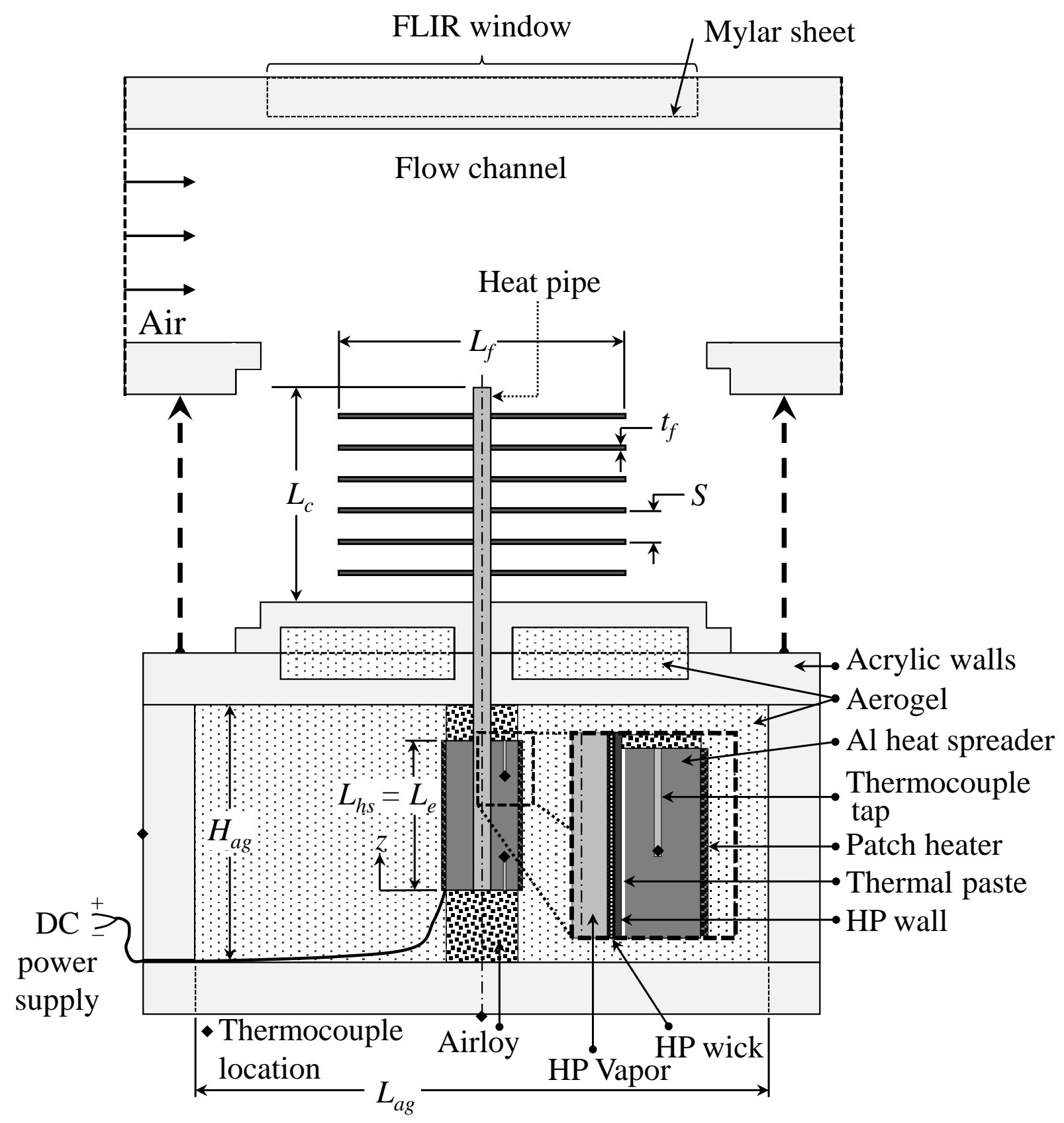

Fig. 3. 


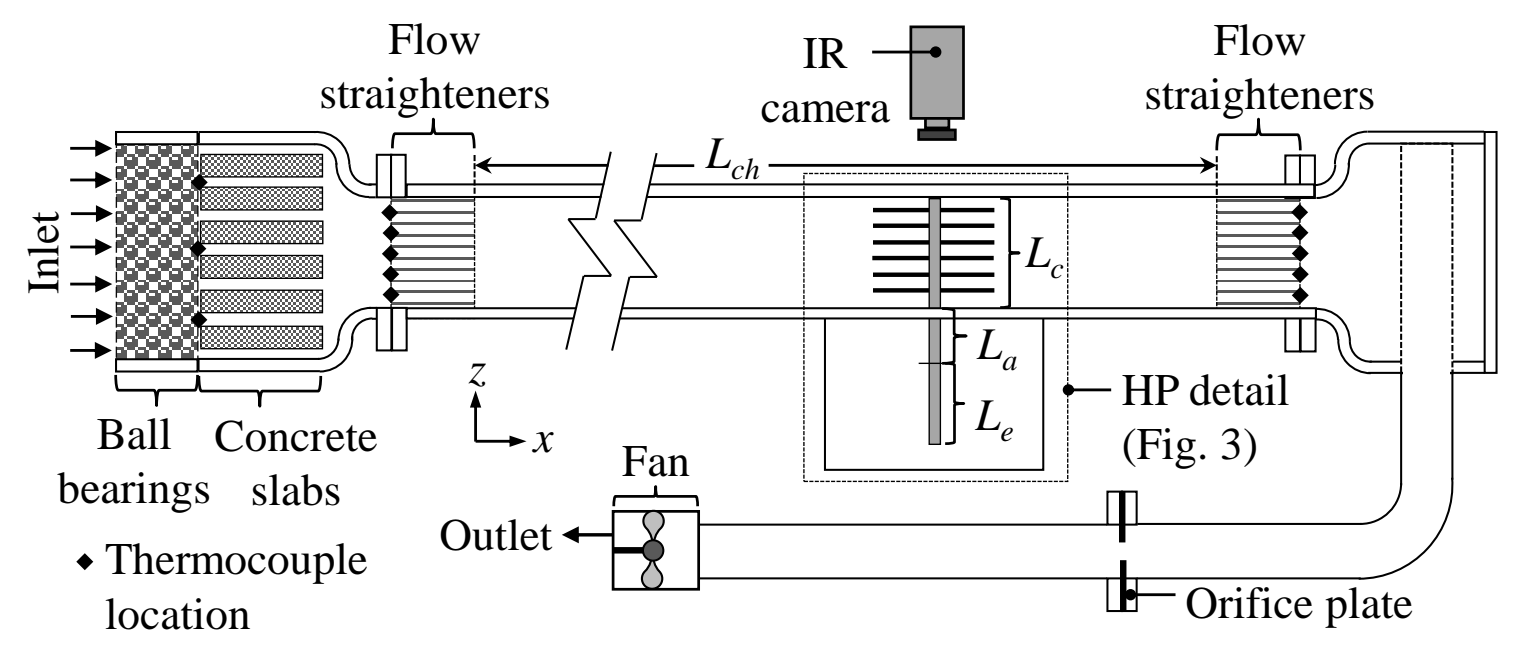

Fig. 4. 


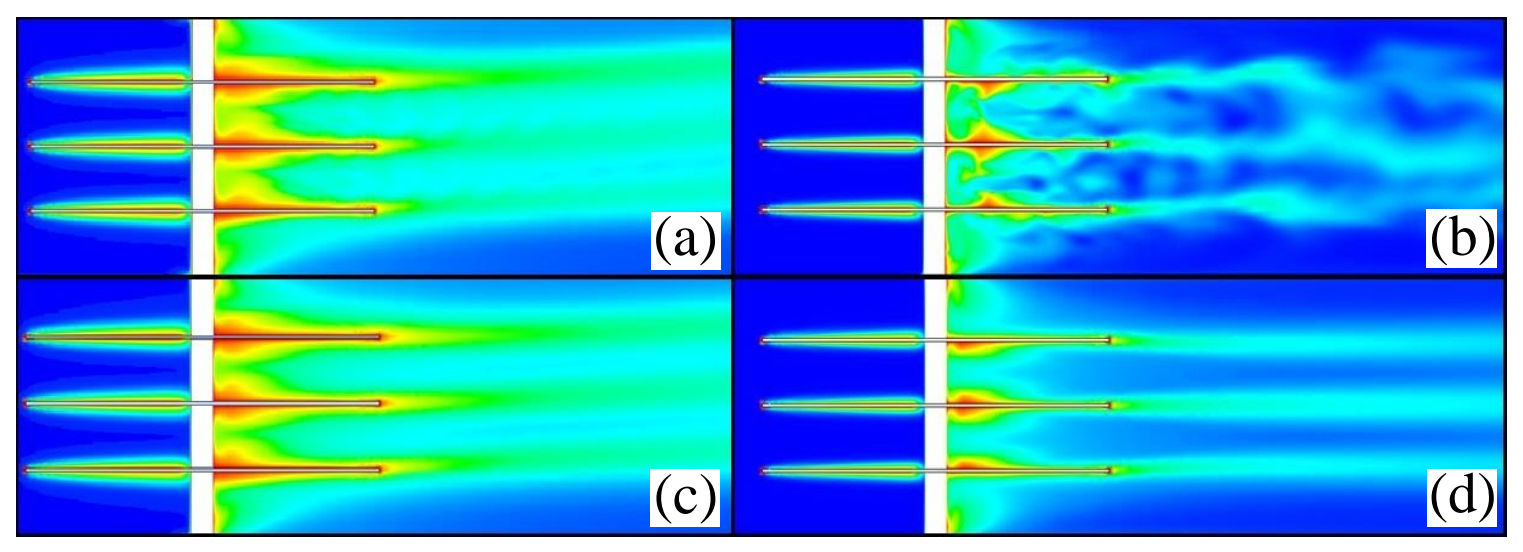

B/W FOR PRINT COPY

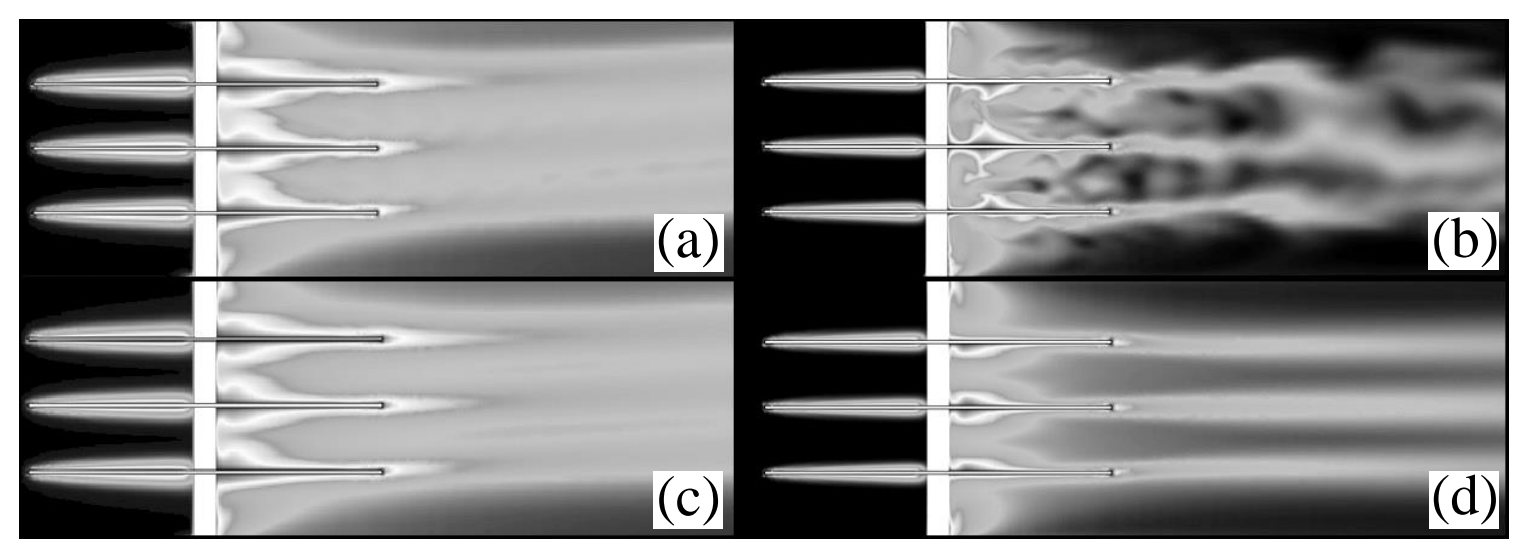

Fig. 5. 


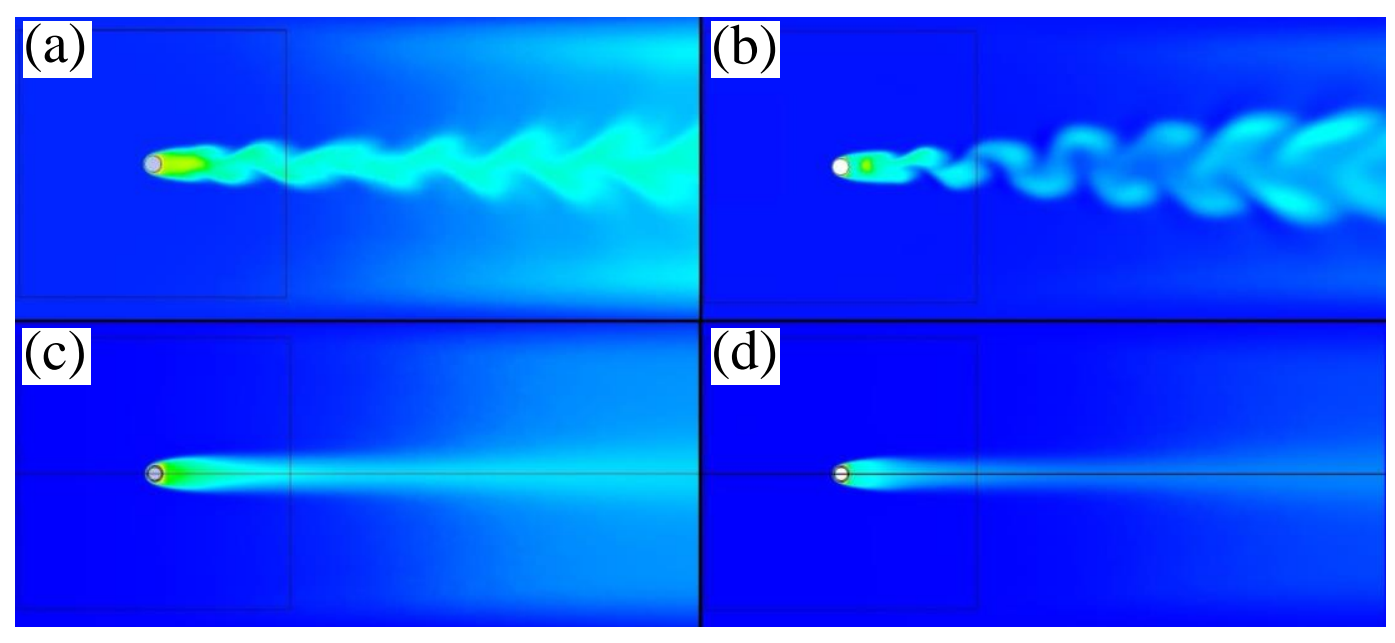

B/W FOR PRINT COPY

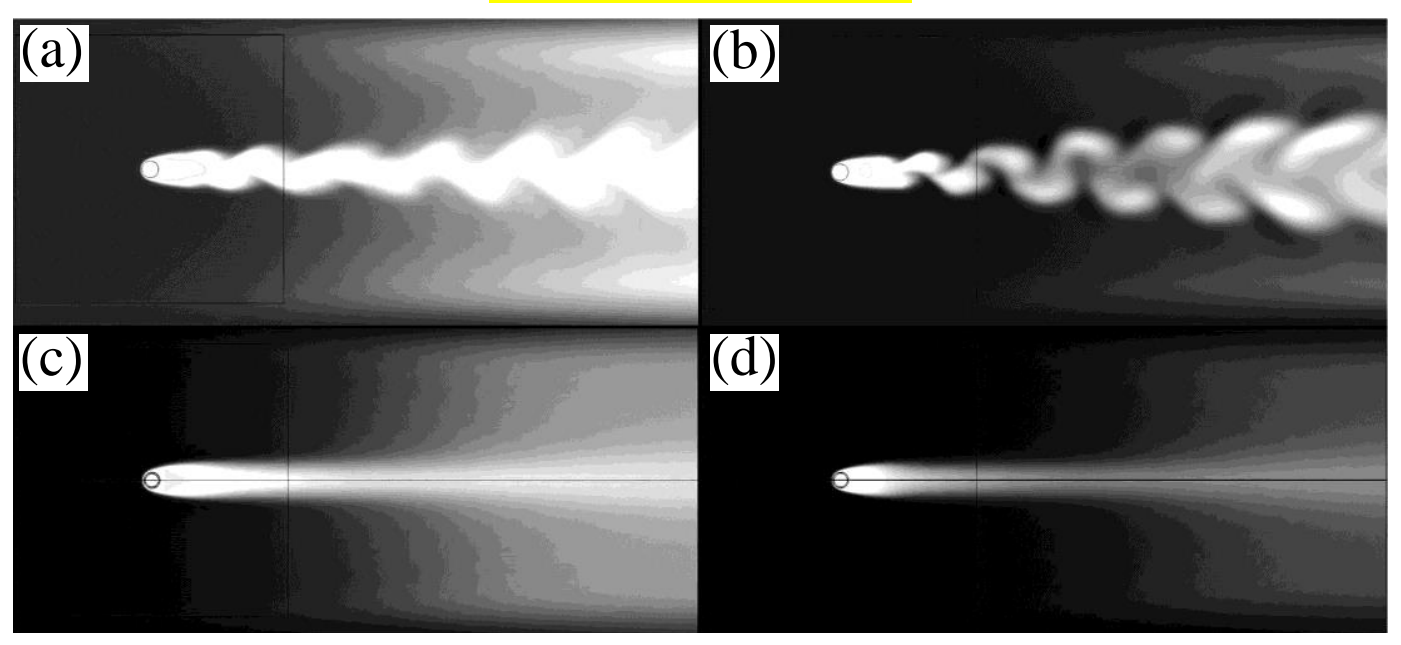

Fig. 6. 

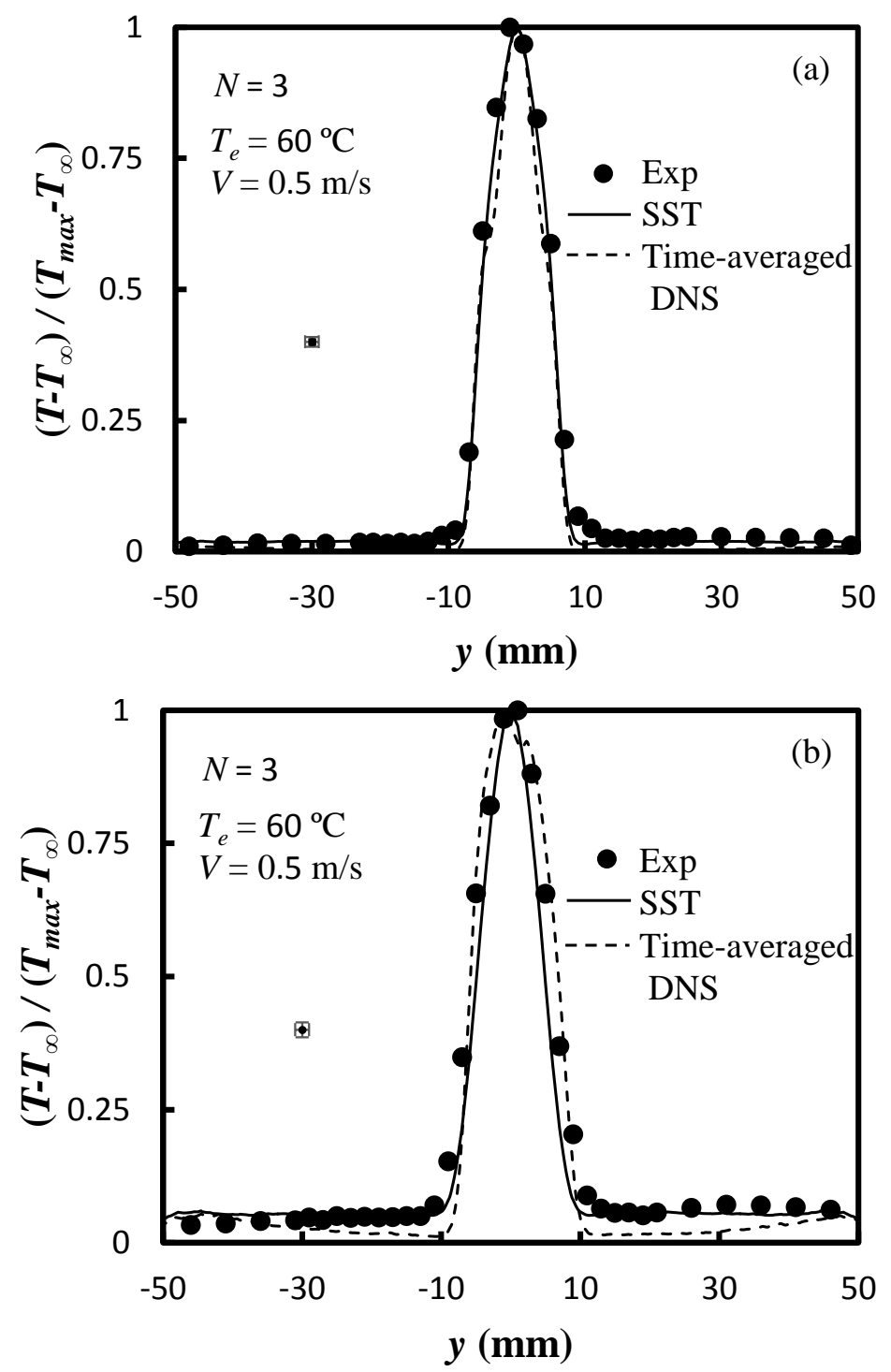

Fig. 7. 


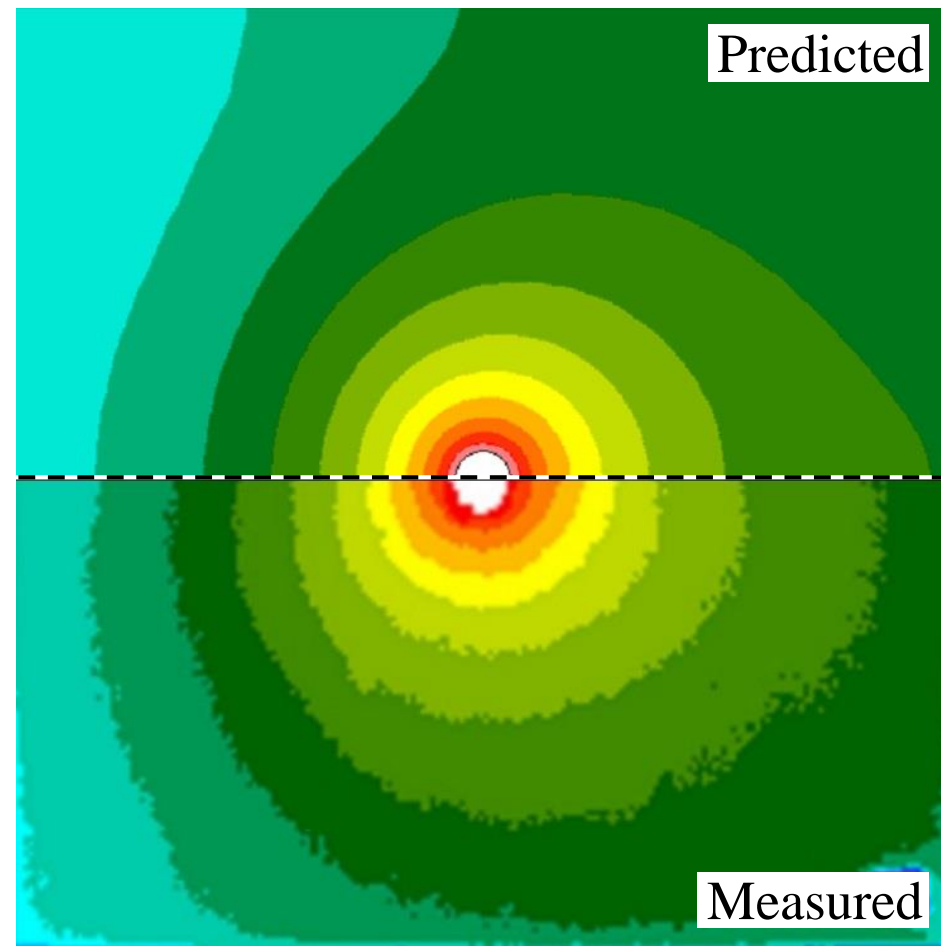

B/W FOR PRINT COPY

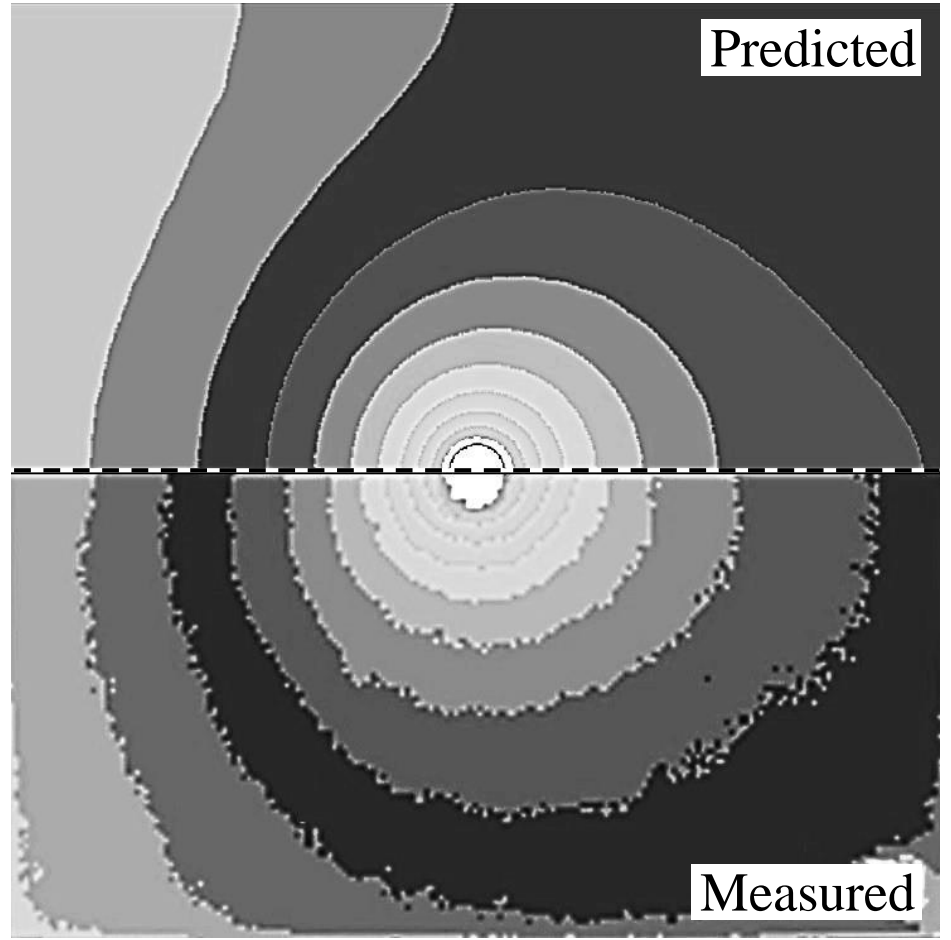

Fig. 8. 

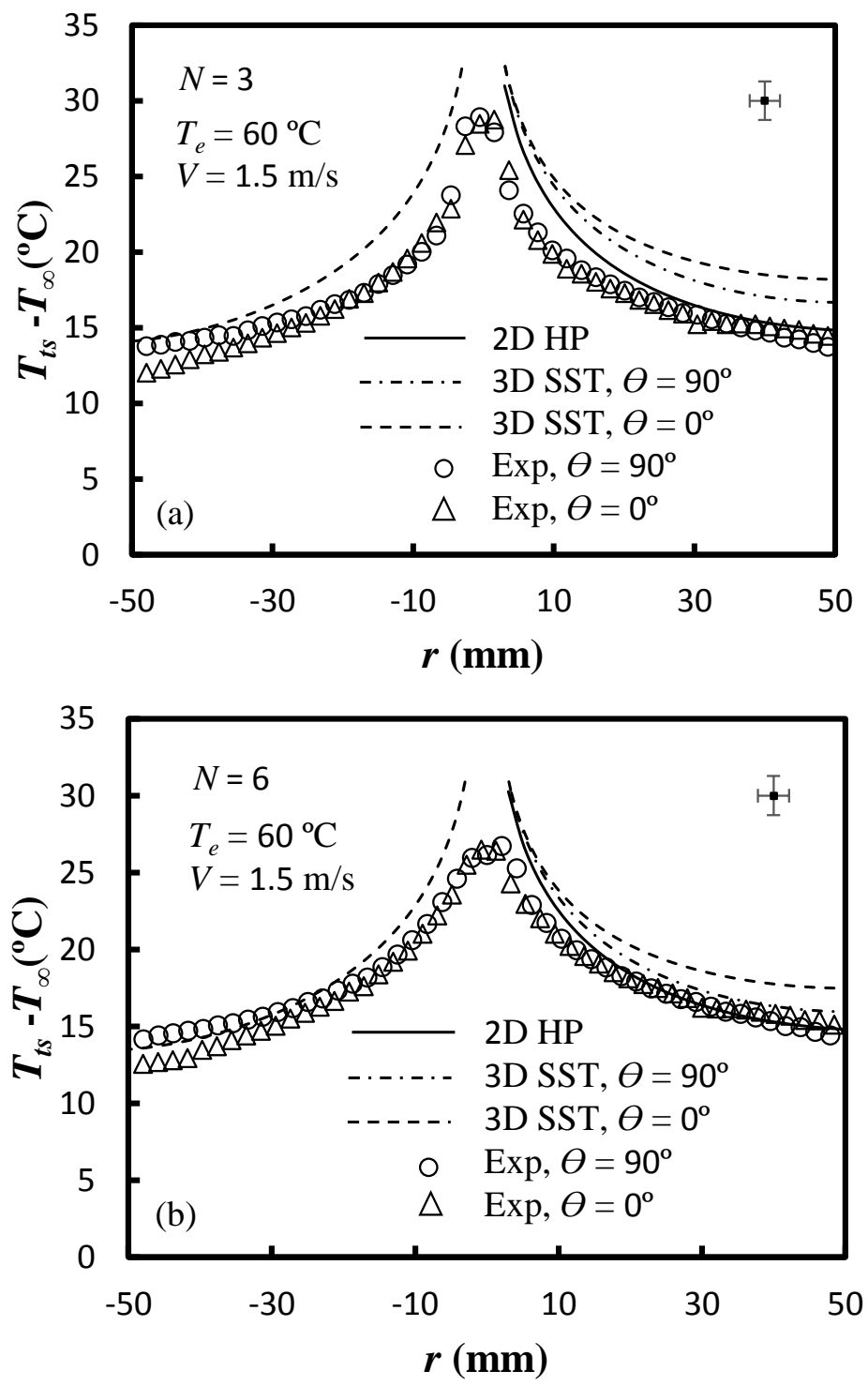

Fig. 9. 

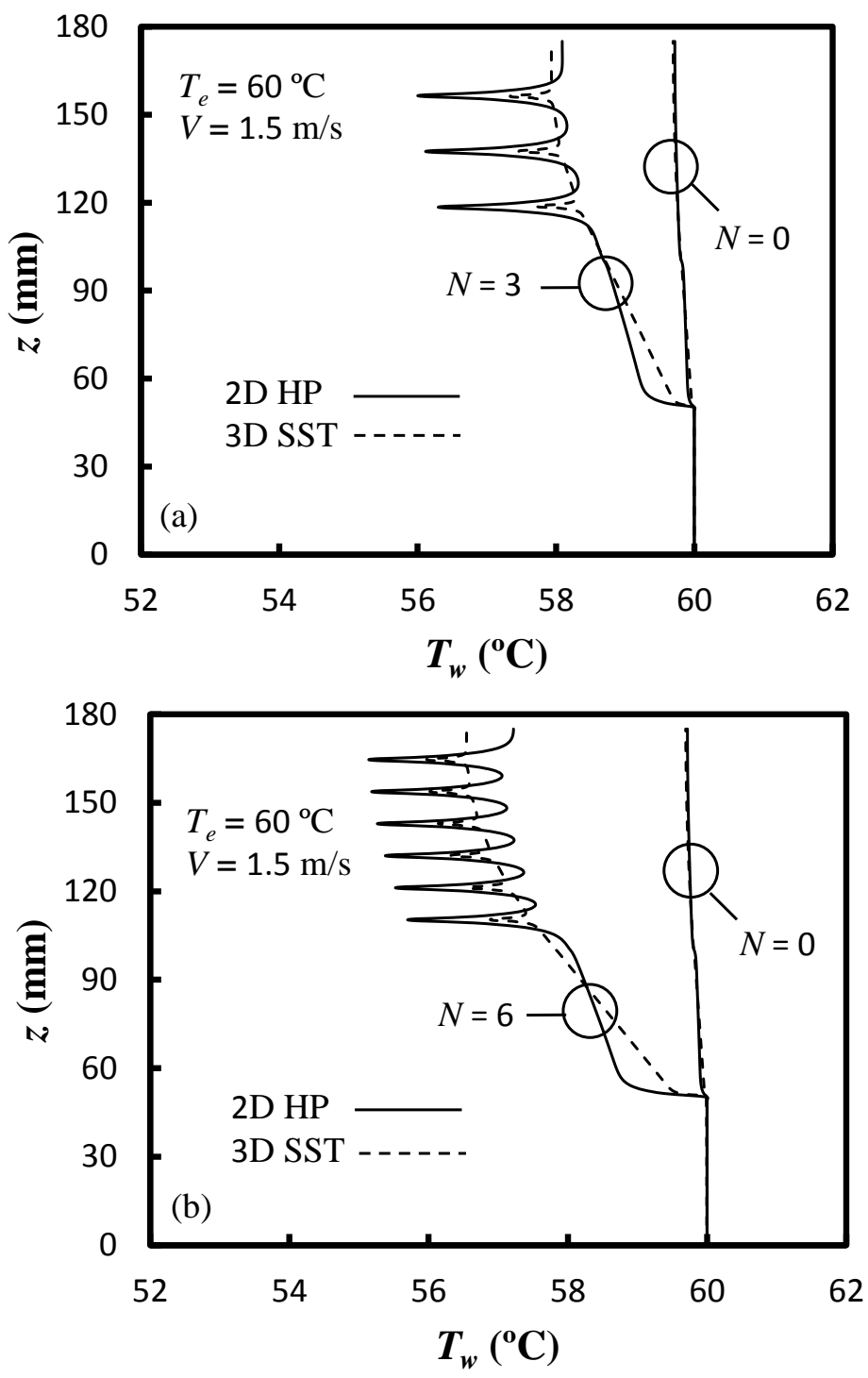

Fig. 10 . 

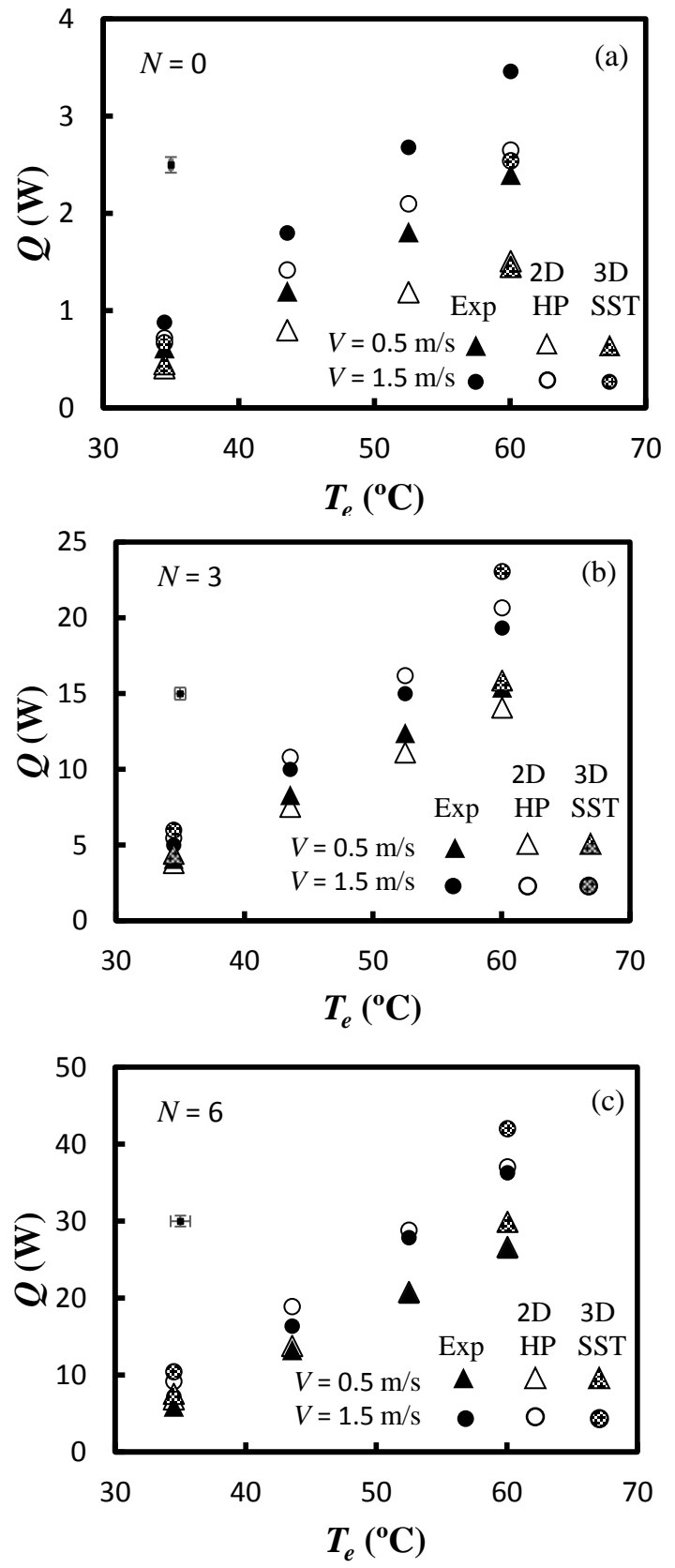

Fig. 11. 


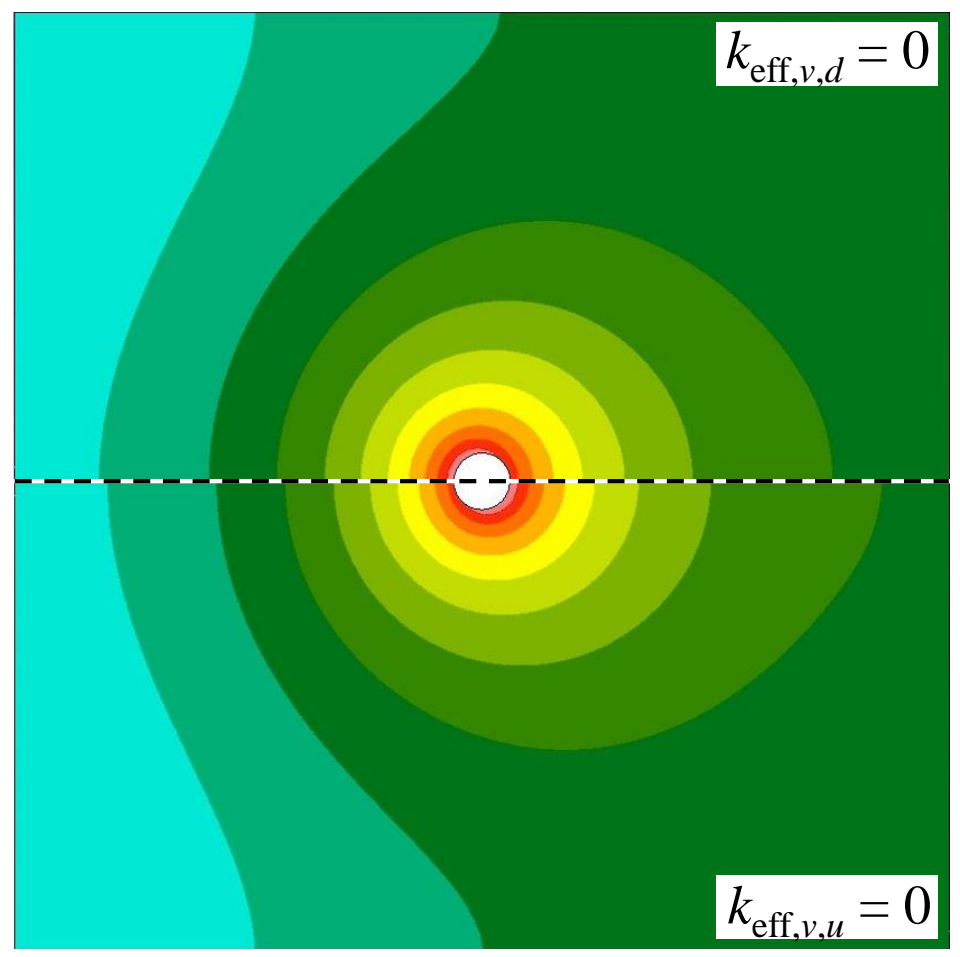

B/W FOR PRINT COPY

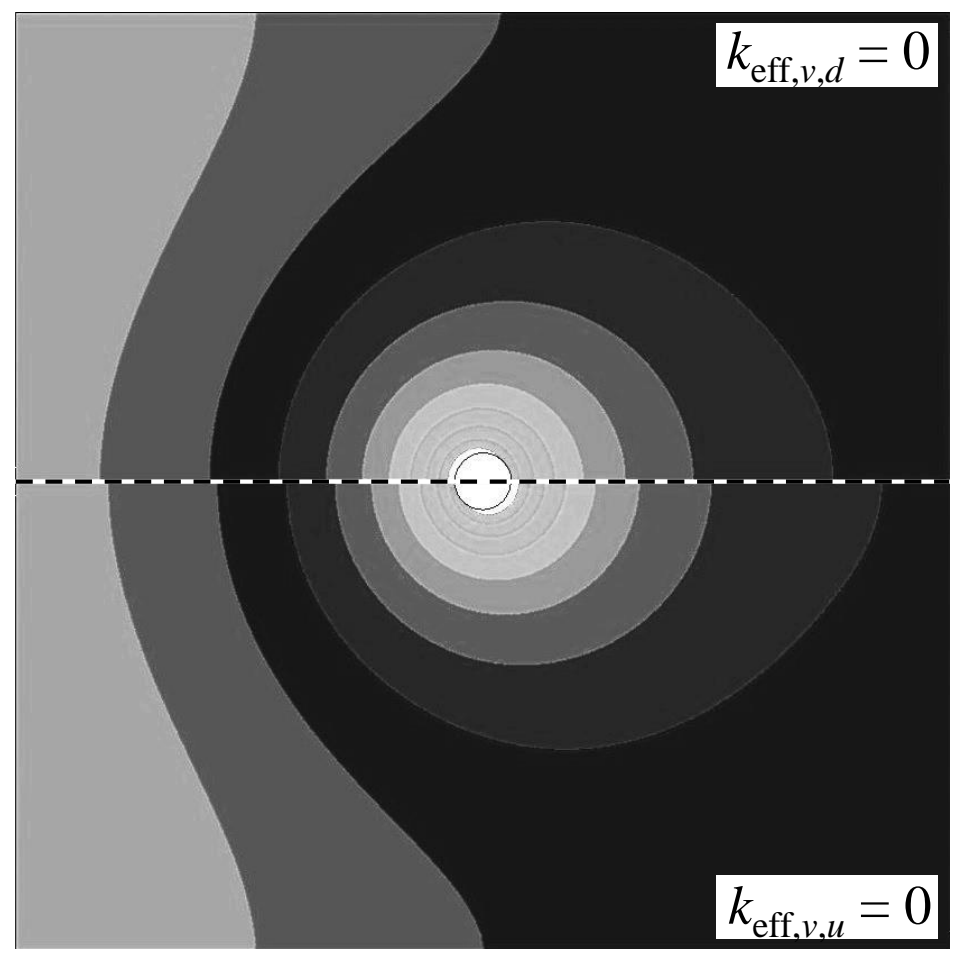

Fig. 12. 


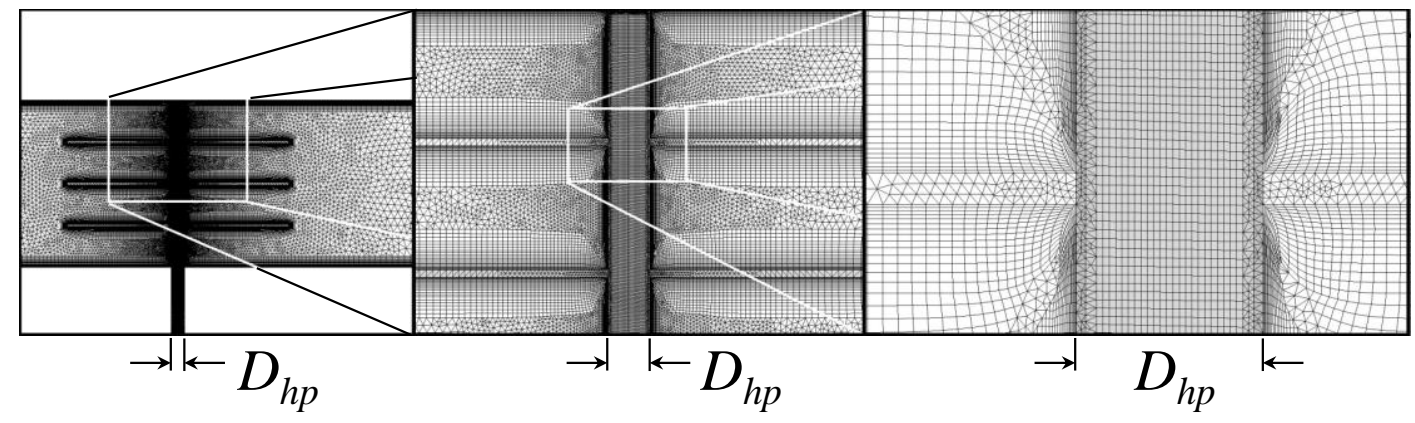

Fig. A-1. 